\title{
Rodent Medial Frontal Control of Temporal Processing in the Dorsomedial Striatum
}

\author{
DEric B. Emmons, ${ }^{1}$ Benjamin J. De Corte, ${ }^{1}$ Youngcho Kim, ${ }^{1}$ Krystal L. Parker, ${ }^{2}$ Matthew S. Matell, ${ }^{3}$ \\ and Nandakumar S. Narayanan ${ }^{1}$ \\ ${ }^{1}$ Department of Neurology and ${ }^{2}$ Department of Psychiatry, University of Iowa, Iowa City, Iowa 52242, and ${ }^{3}$ Department of Psychological and Brain Sciences, \\ Villanova University, Villanova, Pennsylvania 19085
}

\begin{abstract}
Although frontostriatal circuits are critical for the temporal control of action, how time is encoded in frontostriatal circuits is unknown. We recorded from frontal and striatal neurons while rats engaged in interval timing, an elementary cognitive function that engages both areas. We report four main results. First, "ramping" activity, a monotonic change in neuronal firing rate across time, is observed throughout frontostriatal ensembles. Second, frontostriatal activity scales across multiple intervals. Third, striatal ramping neurons are correlated with activity of the medial frontal cortex. Finally, interval timing and striatal ramping activity are disrupted when the medial frontal cortex is inactivated. Our results support the view that striatal neurons integrate medial frontal activity and are consistent with drift-diffusion models of interval timing. This principle elucidates temporal processing in frontostriatal circuits and provides insight into how the medial frontal cortex exerts top-down control of cognitive processing in the striatum.
\end{abstract}

Key words: dorsomedial striatum; medial frontal cortex; medium spiny neurons; Parkinson's disease; prefrontal cortex; timing

\section{Significance Statement}

The ability to guide actions in time is essential to mammalian behavior from rodents to humans. The prefrontal cortex and striatum are critically involved in temporal processing and share extensive neuronal connections, yet it remains unclear how these structures represent time. We studied these two brain areas in rodents performing interval-timing tasks and found that timedependent "ramping" activity, a monotonic increase or decrease in neuronal activity, was a key temporal signal. Furthermore, we found that striatal ramping activity was correlated with and dependent upon medial frontal activity. These results provide insight into information-processing principles in frontostriatal circuits.

\section{Introduction}

Time is a fundamental and highly conserved dimension of mammalian behavior (Buhusi and Meck, 2005; Merchant et al., 2013; Merchant and de Lafuente, 2014). The frontal cortex and striatum are key brain structures for time-based decision making (Meck, 2006; Coull et al., 2011; Narayanan et al., 2012). For example, lesions of either area impair the temporal control of action (Coull et al., 2011). Furthermore, patients with impaired frontostriatal circuits (e.g., Parkinson's disease, schizophrenia, etc.) have timing deficits (Malapani et al., 1998; Ward et al., 2012;

\footnotetext{
Received May 19, 2017; revised July 31, 2017; accepted Aug. 2, 2017.

Author contributions: E.B.E. and N.S.N. designed research; E.B.E. and K.L.P. performed research; E.B.E., B.J.D.C., Y.K., and N.S.N. analyzed data; E.B.E., B.J.D.C., M.S.M., and N.N. wrote the paper.

This work was supported by funding from the National Institutes of Health (R01 to N.S.N. and B.J.D.C.; National Research Service Award to E.B.E.; R15 to M.S.M.).

The authors declare no competing financial interests.

Correspondence should be addressed to Nandakumar Narayanan, 169 Newton Road, Pappajohn Biomedical Discovery Building — 1336, University of lowa, lowa City, IA 52242. E-mail: Nandakumar-narayanan@uiowa.edu. DOI:10.1523/JNEUROSCI.1376-17.2017

Copyright $\odot 2017$ the authors $\quad 0270-6474 / 17 / 378718-16 \$ 15.00 / 0$
}

Parker et al., 2015a, 2017; Kim et al., 2017). Single neurons throughout the frontal cortex and the striatum are prominently modulated across temporal delays (Kimchi and Laubach, 2009; Narayanan and Laubach, 2009a; Ma et al., 2014a; Donnelly et al., 2015). Despite these data, it is unclear how frontal and striatal neurons interact during timing tasks. Establishing the principles of frontostriatal interaction is particularly significant for understanding corticostriatal-thalamic loops and human diseases that affect these circuits (Alexander and Crutcher, 1990; Parker et al., 2016).

Here, we studied frontostriatal circuits using an intervaltiming task in rodents (Buhusi and Meck, 2005). During this task, rodents indicate their internal estimate of time by making a motor response several seconds after the onset of an instructional cue. Across many behavioral contexts, the rodent medial frontal cortex (MFC) is critical for timing behavior. Indeed, disrupting this area impairs the temporal control of action without affecting motor control per se (Risterucci et al., 2003; Narayanan et al., 2006; Kim et al., 2009; Parker et al., 2014b; Narayanan and Laubach, 2017). Neurons in the rodent MFC project prominently 
A

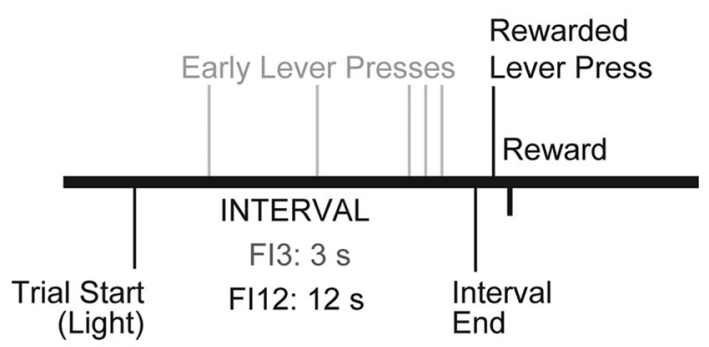

B

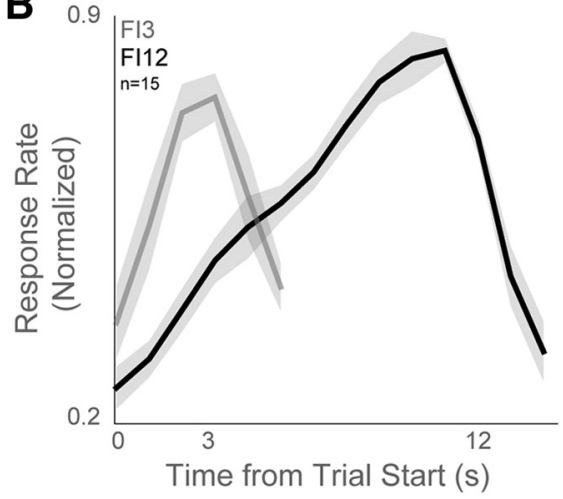

Figure 1. Fixed-interval timing task and behavior. $A$, We studied fixed-interval timing using a task in which rodents estimate an interval of several seconds ( 3 s interval on FI3 trials; $12 \mathrm{sinterval}$ on FI12 trials) by making a lever press; early responses are unreinforced. $\boldsymbol{B}$, Time-response histograms on Fl3 trials (gray) and FI12 trials (black).

to the dorsomedial striatum (DMS; Gabbott et al., 2005; Wall et al., 2013). One common pattern of neuronal firing in both the MFC and the striatum is time-dependent ramping activity, monotonic increases or decreases in firing rate across time (Matell et al., 2003; Kim et al., 2013, 2017; Parker et al., 2014b, 2017; Donnelly et al., 2015; Gouvea et al., 2015; Mello et al., 2015; Narayanan, 2016). If ramping activity in the striatum is guided by the MFC and represents the passage of time, inactivating the MFC should diminish striatal ramping activity and disrupt timing behavior.

We tested this hypothesis by recording from neuronal ensembles in the rodent MFC and DMS during a fixed-interval timing task in which distinct cues instructed rats to respond after 3 or 12 s elapsed. We then inactivated the MFC and evaluated whether this attenuated ramping activity in the DMS. We focused on medium spiny neurons (MSNs) as they are the primary output cell type from the striatum (Chuhma et al., 2011). We report that (1) ramping activity is ubiquitous throughout frontostriatal networks, (2) frontostriatal ensemble activity scales across multiple intervals and encodes temporal information, (3) DMS ramping activity is correlated with MFC ramping activity and with cuetriggered 4-Hz MFC oscillations, and (4) MFC inactivation attenuates interval-timing behavior as well as striatal ramping activity. Our data demonstrate how MFC neurons exert top-down control over MSNs during interval timing and provide insight into fundamental information-processing principles of frontostriatal circuits.

\section{Materials and Methods}

Rodents. Fifteen male Long-Evans rats were trained on an interval-timing task with a standard operant approach described in detail previously (Narayanan et al., 2012; Parker et al., 2014b). Operant chambers (MedAssociates), enclosed in sound-attenuating cabinets, were equipped with a lever, a drinking tube, and a speaker driven to produce an $8 \mathrm{kHz}$ tone at $72 \mathrm{~dB}$. Water rewards were delivered via a pump (MedAssociates) connected to a metal drinking spout (AnCare) via Tygon tubing and located immediately to the right of the lever. First, animals were trained to press a lever for water reward using a fixed-ratio task. Then, animals were trained on a $12 \mathrm{~s}$ fixed-interval task (FI12). In this task, trials began with the presentation of a houselight at trial onset (time 0 ) and the first response made after $12 \mathrm{~s}$ had passed resulted in reward delivery, a concurrent click sound, and termination of the houselight (Fig. 1A). Responses made before $12 \mathrm{~s}$ elapsed had no programmed consequence. Trials were separated by a $6,8,10$, or $12 \mathrm{~s}$ intertrial interval that was randomly chosen. Sessions lasted $60 \mathrm{~min}$. The timing of each response was used to compute average response rate as a function of time within a trial. To compare across animals, response rates were normalized to the highest average response rate during the interval. Average response time on each trial served as the measure of central tendency for trial-by-trial correlations with neural activity. Later in the experimental sequence, a second delay of $3 \mathrm{~s}$ was added. This $3 \mathrm{~s}$ interval (FI3) was signaled with an additional light on the right side of the lever.

Past work has indicated that with the lever and spout right next to each other, animals spend most of their time at the reward spout with their paw next to the lever (Narayanan and Laubach, 2006, 2009a; Narayanan et al., 2006, 2013; Parker et al., 2014b, 2015b; Emmons et al., 2016). They occasionally engage in very brief grooming or exploratory deviations immediately after collecting rewards or during the intertrial interval. To quantify any time-dependent behaviors outside of lever-pressing activity, we used a machine-learning approach (Gouvea et al., 2015). A 3D infrared depth camera (Intel SR300) was used to capture depth and video data during rodent behavior at 30 frames/s. Because this camera was positioned to capture movements of the entire animal, video analyses did not detect individual licks or lever presses; however, the precise timing of these events was obtained from our behavioral devices. The backgroundsubtracted image sequence was generated by Gaussian mixture-based background segmentation based on depth and color video data. To identify task-relevant features with principal component analysis (PCA), images were downsampled at $226 \times 316$ pixels and at 10 frames/s. PCA is a standard technique used for dimension reduction, although there are alternative approaches (Witten and Frank, 2000; Joliffe, 2002; Xu and Li, 2003). The first 10 principal component features were used to predict time from video data. A naive Bayesian classifier (NBC) implemented in MATLAB ( fitcnb.m) was used to predict objective time from principal component video features using leave-one-out cross-validation. Approach behavior was quantified by two independent raters based on video of animals in saline and muscimol sessions. Approach time was defined as the interval between the start of the trial and the time that the animal first moved toward the lever.

Surgical and histological procedures. Fifteen rats trained in the intervaltiming task were implanted with a microwire array in the MFC and/or DMS according to procedures described previously (Parker et al., 2014b; Emmons et al., 2016). Five rats had recording electrodes in the MFC and DMS, six rats had DMS recording electrodes and bilateral infusion cannulae in the MFC, and four rats had only unilateral MFC recording electrodes. Minimum sample size for each group ( $\geq 4$ per group; 5 animals in combined MFC/DMS recordings, 6 animals in MFC inactivation/DMS recordings, 4 animals with only MFC arrays) was determined from power analysis based on the average number of neurons recorded from each electrode $(0.8$ neurons/electrode $\times 16$ electrodes $=12.8$ neurons/array; $\alpha=0.05, \beta=0.2$ ). Briefly, animals were anesthetized using ketamine $(100 \mathrm{mg} / \mathrm{kg})$ and xylazine $(10 \mathrm{mg} / \mathrm{kg})$. A surgical level of anesthesia was maintained with hourly (or as needed) ketamine supplements $(10 \mathrm{mg} / \mathrm{kg})$. Under aseptic surgical conditions, the scalp was retracted and the skull was leveled between bregma and lambda. In different groups of animals, craniotomies were drilled above the left MFC and/or 
the left DMS and four holes were drilled for skull screws, which were connected to electrode recording arrays via a separate ground wire. Microelectrode arrays consisted of $50 \mu \mathrm{m}$ stainless-steel wires $(250 \mu \mathrm{m}$ between wires and rows; impedance measured in vitro at $\sim 400 \mathrm{k} \Omega$; Plexon) configured in either $4 \times 4$ or $2 \times 8$ orientations. Arrays were implanted in the MFC [coordinates from bregma: anteroposterior (AP), $+3.2 \mathrm{~mm}$; mediolateral (ML), $\pm 1.2 \mathrm{~mm}$; dorsoventral (DV), $-3.6 \mathrm{~mm}$; $12^{\circ}$ in the lateral plane; these coordinates target the dorsal prelimbic cortex, as in our prior work; Parker et al., 2014b; Emmons et al., 2016], DMS (coordinates from bregma: AP, $+0.0 \mathrm{~mm}$; ML, $\pm 4.2 \mathrm{~mm}$; DV, $-3.6 \mathrm{~mm} ; 12^{\circ}$ in the posterior plane), or both areas (Fig. $1 B$ ). Electrode arrays were inserted while recording neuronal activity to verify implantation in layer II/III of the MFC or in the most dorsal portion of the DMS. The craniotomy was sealed with cyanoacrylate accelerated by ZipKicker (Pacer Technologies) and covered with methyl methacrylate (i.e., dental cement; AM Systems). Following implantation, animals recovered for 1 week before being reacclimatized to behavioral and recording procedures.

Following experiments, rats were anesthetized and killed with injections of $100 \mathrm{mg} / \mathrm{kg}$ sodium pentobarbital, and transcardially perfused with $4 \%$ formalin. Brains were post-fixed in a solution of $4 \%$ formalin and $20 \%$ sucrose before being sectioned on a freezing microtome. Brain slices were mounted on gelatin-coated slides and stained for cell bodies using either DAPI or cresyl violet. Histological reconstruction was completed using postmortem analysis of electrode placements by confocal microscopy or stereology microscopy in each animal. These data were used to determine electrode and cannula location within MFC and electrode location in the DMS (Fig. 1B).

Rodent experimental protocol. Rats were first trained in the fixed interval-timing task with 12-s intervals (FI12) and then implanted with microelectrode arrays and/or cannulae, as described above. After animals were acclimatized to recording procedures, an additional 3-s interval (FI3) was added to the task. Animals were trained on the two-interval timing task (FI3 and FI12) until behavior stabilized ( $<4$ d). Neuronal recordings in this study were taken during two-interval task performance on subsequent days. In the animals implanted with MFC cannulae and DMS electrodes, saline and muscimol infusions were done on separate days. On the first day of the infusion protocol, animals received bilateral saline infusions through cannulae in the MFC. The following day, animals were infused with the $\mathrm{GABA}_{\mathrm{A}}$ receptor agonist muscimol, which we have previously used to inhibit cortical neuronal activity (Parker et al., 2014b). All recording experiments and drug infusions treated each session as statistically independent (Narayanan et al., 2006, 2013; Narayanan and Laubach, 2008; Parker et al., 2014b).

Neurophysiological recordings and neuronal analyses. Neuronal ensemble recordings were made using a multielectrode recording system (Plexon). Putative single neuronal units were identified on-line using an oscilloscope and an audio monitor. A Plexon Offline Sorter was used to analyze the signals after the experiments and to remove artifacts. Spike activity was analyzed for all cells that fired at rates $>0.1 \mathrm{~Hz}$. PCA and waveform shape were used for spike sorting. In the DMS, we classified putative neurons as either MSNs or interneurons based on peak-to-trough ratio and spike half-peak width of spike waveforms (Berke et al., 2004). Single units were identified as having (1) consistent waveform shape, (2) separable clusters in PCA space, and (3) a consistent refractory period of $\geq 2$ $\mathrm{ms}$ in interspike interval histograms. Analysis of neuronal activity and quantitative analysis of basic firing properties were carried out using NeuroExplorer (Nex Technologies), and with custom routines for MATLAB. Perievent rasters and average histograms were visualized around houselight and lever press events. In each animal, one electrode without single units was reserved for local referencing, yielding 15 electrodes per rat. Local field potentials (LFPs) were recorded from four low-noise electrodes per rodent. LFP channels were analog-filtered between 0.7 and $100 \mathrm{~Hz}$ on-line, sampled at $1000 \mathrm{~Hz}$, and recorded in parallel with single-unit channels using a wide-band board. Although examples of individual neurons are shown under different drug conditions (control and MFC muscimol), our statistical analyses assume that these populations of neurons are independent. This is consistent with our practice in prior work (Narayanan et al., 2006, 2013; Narayanan and Laubach, 2008; Parker et al., 2015b).

Similar to past work from our group, we defined cue-related neurons as those with $p<0.05$ assessed via paired $t$ test of firing rates $250 \mathrm{~ms}$ before cue versus $250 \mathrm{~ms}$ after cue (Narayanan and Laubach, 2006, 2009a; Parker et al., 2014b). We defined lever press-related neurons as those with $p<0.05$ measured by a paired $t$ test of firing rates $250 \mathrm{~ms}$ before lever press versus $250 \mathrm{~ms}$ after lever press, or the $125 \mathrm{~ms}$ centered on lever press versus $125 \mathrm{~ms}$ before and after this epoch. To capture lever pressing in detail, we also turned to linear models, where the dependent variable was firing rate on a given trial $250 \mathrm{~ms}$ after lever press and the independent variables were (1) the duration of lever press (i.e., the time between lever press and release) and (2) the time in the interval the lever was pressed.

We defined time-related ramping activity as firing rate that progressed monotonically over the whole interval, expressed as follows (Eq. 1):

$$
Y=m x+b .
$$

Here $Y$ is the firing rate, $x$ is time in the interval, $m$ is the slope, and $b$ is the intercept. Neurons with a significant fit were quantified by assessing the variance explained by the linear model (ANOVA). The MATLAB function fitlm was used for linear models and the function anova was used to determine significance. To parse lever-pressing activity from ramping activity, we used two approaches. First, we analyzed ramping activity by excluding neurons with press-related activity as described above. Second, we used a linear model to predict firing rate from ramping effects and press-related activity over the whole recording session to explicitly factor out motor responses from ramping activity. To do this, we used the following formula (Eq. 2):

$$
Y(t)=b+m_{1} * I(t)+m_{2} * R(t) .
$$

Here $t$ is time in the session at $100 \mathrm{~ms}$ bins, $I(t)$ is a linear ramp on each trial, and $R(t)$ is the time of each lever press convolved with a Gaussian kernel. As above, we use the MATLAB function fitlm.

To match trials between sessions with MFC active and inactive, we calculated the middle tertile of responses for session with MFC active, as we have done in prior studies (Parker et al., 2014b). Only trials from sessions with MFC inactive with average response times that matched the middle tertile of response times of the MFC active sessions were included in our calculations of ramping activity. We used a repeated-measures ANOVA (aov in R) to examine the effect of MFC inactivation with the following model (Eq. 3):

$$
Y \sim x * T+\operatorname{Error}(1 / \text { neuron }) .
$$

Here, $T$ is the time in the interval each lever press occurred, $x$, on press-related neural firing rate, $Y$. Only lever presses $>0.5 \mathrm{~s}$ in the trial were included. Neuron-specific variance was accounted for. Neurons were assumed to be independent over days.

Joint peristimulus time histograms (JPSTHs) were calculated according to methods described in detail in prior work (Narayanan and Laubach, 2009b). This analysis was only done on FI12 trials. Briefly, JPSTHs were computed at multiple bin sizes $(0.001-5 \mathrm{~s})$ during the interval, and the shift-predicted matrix was subtracted from the raw matrix. We also corrected for the effects of lever pressing on JPSTH interactions. The time of each press was convolved with a Gaussian window to generate the mean press function on each trial. Next, we subtracted this press function from the MFC and DMS neuronal firing rate and calculated the JPSTH of residuals. We termed this the "presscorrected" JPSTH. In both traditional and press-corrected JPSTHs, shuffled correlations were generated by randomly permuting trial order for comparisons.

We also evaluated whether ensemble activity in the MFC and DMS scaled over FI3 and FI12 trials (i.e., stretched or compressed) to match the interval being timed. First, we used principal component analysis (PCA) to identify dominant patterns of neuronal activity using orthogonal basis functions from peri-event histograms. PCA was performed separately for FI3 and FI12 trials. All neurons within each experimental paradigm were included in PCA, and the first $500 \mathrm{~ms}$ of the interval were 
excluded due to stimulus-related activity (Chapin and Nicolelis, 1999; Narayanan and Laubach, 2009a; Parker et al., 2015b). To look at ensemble dynamics, we binned each neuron's data in proportion to the duration being timed, such that each bin corresponded to a fixed percentage of the interval ( 30 proportional bins for FI3 and FI12 trials). Then, we computed the speed of the ensemble trajectory during each trial type by treating the firing rate across neurons at each bin as a high-dimensional point in state space-specifically, a neuron-dimensional point with firing rate representing the value on each axis (Stokes et al., 2013). Dividing the Euclidean distance between successive bins by the interbin time interval represents the speed of the ensemble's trajectory in absolute time. In contrast, dividing the distance between successive bins by the percentage of the interval that has elapsed represents the trajectory's rate of change as a function of scaled time. If the ensemble activity scales to match the interval being timed, the trajectory should move four times faster on FI12 versus FI3 trials when evaluated in absolute time. Conversely, in scaled time, the rate of change as a function of the percentage of the interval being timed should be equivalent across the two trial types. We evaluated this by computing the FI3 versus FI12 speed ratio across both absolute and scaled time.

Time-frequency analyses. To examine the time-frequency properties of spike trains, we applied the method of Halliday et al. to calculate the power spectral density for each neuron from each neuron's interspike interval using the discrete Fourier transform (Rosenberg et al., 1989; Halliday et al., 1995). These were calculated using functions in the NeuroSpec toolbox. Power was calculated in 500-ms windows across the $0-12 \mathrm{~s}$ interval and normalized to the preinterval baseline ( -2 to $0 \mathrm{~s}$ ).

LFP data were collected in all animals from each area by filtering $<100 \mathrm{~Hz}$. Time-frequency calculations were computed using customwritten MATLAB routines (Cavanagh et al., 2009). Time-frequency measures were computed by taking the inverse fast Fourier transform (FFT) of the convolution of a FFT LFP power spectrum and a set of complex Morlet wavelets [defined as a Gaussian-windowed complex sine wave, expressed as follows (Eq. 4):

$$
e^{i 2 \pi t f} e^{-\frac{t^{2}}{2 x \sigma^{2}}}
$$

where $t$ is time, $f$ is frequency (increasing from 1 to $50 \mathrm{~Hz}$ in 50 logarithmically spaced steps), and $\sigma$ is scaling, defined as cycles/(2 $2 \mathrm{f})$, with 4 cycle wavelets; Narayanan et al., 2013; Parker et al., 2014b, 2015a; Laubach et al., 2015; Emmons et al., 2016]. We varied the number of cycles and other parameters to balance time-frequency resolution for the bands we were interested in here (delta, theta, alpha, and beta bands) and the time windows used for analysis $(\sim 1 \mathrm{~s})$. Wavelet transformation results in estimates of instantaneous power, which were subsequently normalized to a decibel scale $(10 * \log 10[\operatorname{power}(\mathrm{t}) / \operatorname{power}($ baseline $)])$, allowing a direct comparison of effects across frequency bands.

To examine the time-frequency component of interactions between individual spikes and the field potential, we applied spike-field coherence analysis using the NeuroSpec toolbox (Rosenberg et al., 1989; Narayanan et al., 2013; Parker et al., 2014b), in which multivariate Fourier analysis was used to extract phase locking among spike trains and LFPs. Phaselocking coherence values varied from 0 to 1 , where 0 indicates no coherence and 1 indicates perfect coherence. To compare across neurons with different distributions, all phase-locking values were divided by that neuron's $95 \%$ confidence interval, so that 1 indicates $p<0.05$ (Parker et al., 2015a).

Classification. We evaluated whether time within a trial could be decoded from ensemble activity using a naive Bayesian classifier (NBC). Firing rates from MFC and DMS neurons during individual trials were binned using a sliding window (50-ms width, 25-ms spacing), $z$-scored, and smoothed using a Gaussian kernel over a 1000-ms window. Only FI12 trials were included in this analysis. To prevent edge effects from biasing classifier performance for time within a trial, we included data from $6 \mathrm{~s}$ before trial start and $6 \mathrm{~s}$ after the 12-s interval elapsed. Then, we used leave-one-out cross-validation to predict objective time from firing rate within a trial. We evaluated classifier performance by computing the sum of squared errors (SSEs) between objective time and predicted time for bins that occurred between trial onset and when the 12-s duration elapsed. With perfect classification, the SSE for a trial would equal zero, whereas higher values indicate worse performance. Within-area and across-area comparisons (see below) were evaluated with paired and independent $t$ tests, respectively.

Experimental design and statistical analysis. We recorded neuronal activity in the MFC and DMS during performance of an interval-timing task. Task-specific modulations were evaluated via linear regression, linear models, $\chi^{2}$ tests, or paired $t$ tests as above, consistent with our past work (Parker et al., 2013a, 2014b, 2015b; Kim et al., 2017). All analyses and statistical tests were carried out in MATLAB and R. The effect of MFC inactivation was evaluated using a within-subjects design comparing firing rate and ramping activity between MFC control and inactivation sessions. All statistical analyses assumed that neurons were independent between sessions.

\section{Results}

\section{Ramping activity is prominent in frontostriatal circuits}

We recorded neuronal ensemble activity from rodent frontostriatal circuits as rats performed a fixed-interval task with 3-s (FI3) and 12-s (FI12) intervals. In this task, animals are reinforced with a water reward for pressing a lever 3 or $12 \mathrm{~s}$ after onset of an instructional cue. Early responses were unreinforced (Fig. $1 A$ ). Fifteen animals in this study performed an average of $733 \pm$ 89 lever presses (mean \pm SEM) for an average of $106 \pm 6$ rewards per behavioral session. The average response time on FI3 trials was $4.7 \pm 0.02 \mathrm{~s}$, significantly less than the average on FI12 trials $\left(10.7 \pm 0.05 \mathrm{~s}\right.$, paired $\left.t_{(14)}=25.2, p<10^{-13}\right)$. The first response was significantly earlier during FI3 versus FI12 trials $(1.6 \pm 0.1 \mathrm{~s}$ vs $2.3 \pm 0.3 \mathrm{~s}$, paired $t_{(14)}=2.3, p<0.04$; Fig. $\left.1 B\right)$.

We recorded from the MFC of nine animals and the DMS of 11 animals, five of which had recording arrays in both brain areas (Fig. 2A). We recorded from 77 MFC neurons, or $8.6 \pm 3.4$ neurons/animal ( $\sim 0.5 /$ wire $)$. In the DMS, we identified MSNs according to the clustering of neural waveforms based on peakto-trough ratio and spike half-peak width (Berke et al., 2004; Jin et al., 2014). All interneurons had peak-to-trough durations $<0.25 \mathrm{~ms}$ and half-peak width values $<0.15 \mathrm{~ms}$ (Fig. $2 B$ ). Using these criteria, we identified 89 well-isolated and clustered DMS MSNs from 11 rats with DMS electrodes, or $7.6 \pm 3.3$ neurons/ animal $(\sim 0.5 /$ wire $)$. All subsequent analyses are restricted to these well clustered MSNs. Notably, we used stringent spikesorting criteria to exclude equivocal neurons or interneurons in both MFC and DMS, accounting for the slightly lower yield of neurons here compared with our past work (Parker et al., 2014b, 2015a).

We observed one notably prominent pattern of neuronal activity in the MFC and DMS: time-dependent ramping. We defined time-dependent ramping activity as a monotonic increase or decrease in neuronal activity across the interval as assessed by linear fit of firing rate over time (Fig. $3 A, B$; blue, MFC; green, DMS). Frontostriatal neurons could ramp up or down (Fig. $3 A, B$ ), and ramping was common in the MFC and DMS neuronal populations (Fig. $3 C, D$ ). To further quantify the firing characteristics of ramping neurons, we sorted ramping neurons by regression slope into those that ramped up or down during FI12 trials (Fig. $3 E, F$ ). There were nine up-ramping neurons in the MFC (12\% of all MFC neurons) compared with 22 in the DMS (25\% of all DMS neurons), and 20 down-ramping neurons in the MFC (26\%) compared with 18 in the DMS (20\%). The slope of MFC neurons over the interval (regardless of valence of slope) on FI12 trials was $0.27 \pm 0.18$ spikes $/ \mathrm{s}^{2}$, compared with $0.40 \pm 0.18$ spikes $/ \mathrm{s}^{2}$ in the DMS (Fig. $3 E, F$ ). These data are in line with past work describing ramping activity in frontostriatal ensembles (Donnelly et al., 2015; Gouvea et al., 2015; Narayanan, 2016). 
A

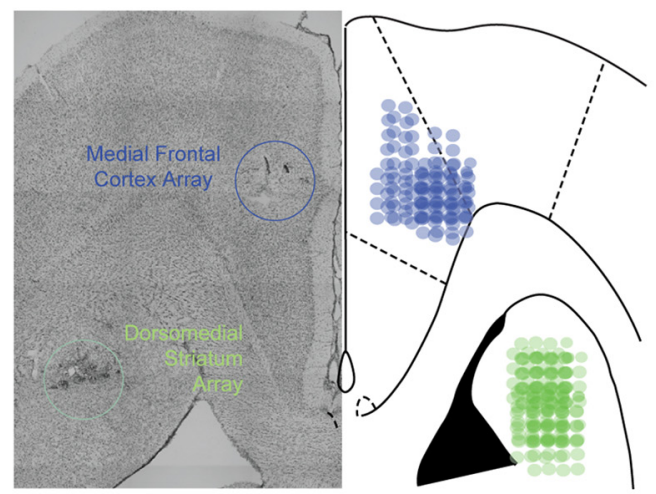

Horizontal Section @ DV -3.6
B

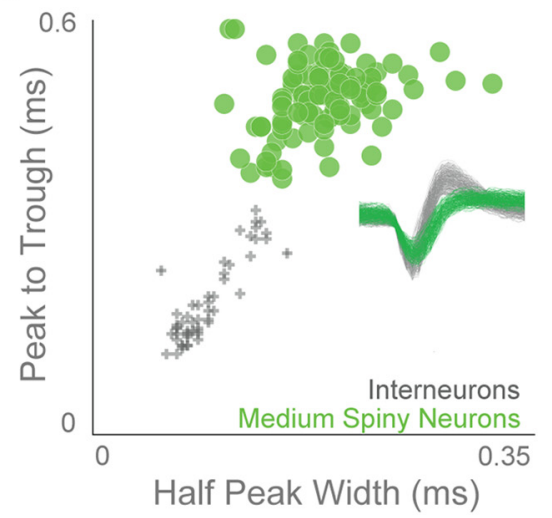

Figure 2. Electrophysiological recordings. A, We implanted 15 animals with recording electrodes in the MFC ( 9 rats; blue) or DMS ( 11 rats, green; 6 of these rats also had bilateral MFC cannulae while the other 5 also had MFC electrode arrays). Horizontal section shown at $\sim$ DV $-3.6 \mathrm{~mm}$. B. We only report data from 89 well isolated DMS MSNs that cluster distinctly from other striatal neuronal classes as plotted by peak-to-trough duration and half-peak-width.

A

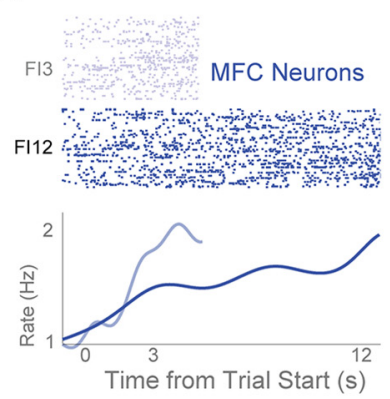

B
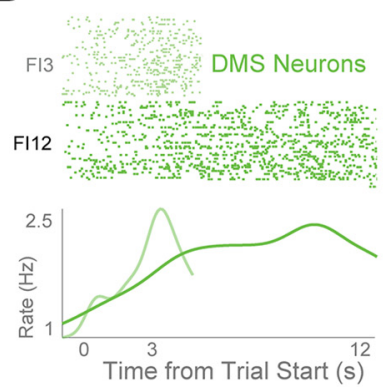
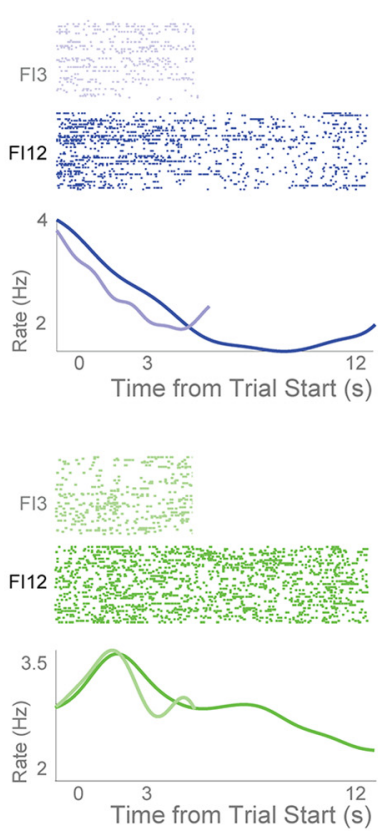

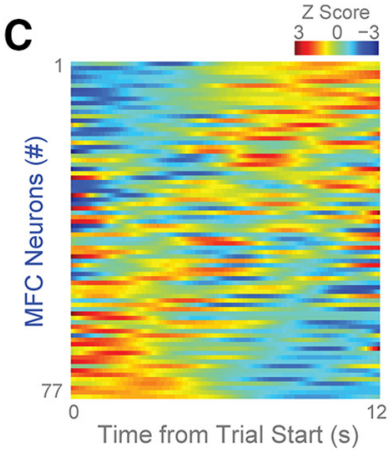

D

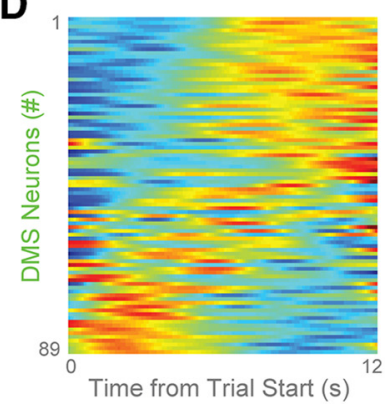

$\mathbf{E}$

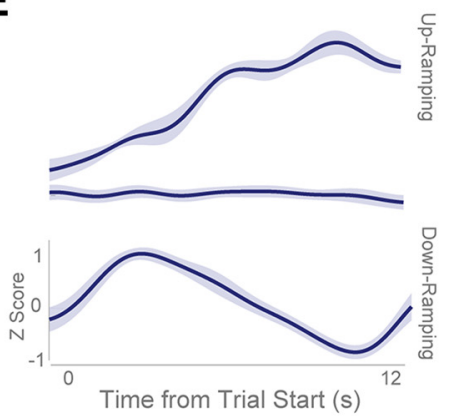

$\mathbf{F}$

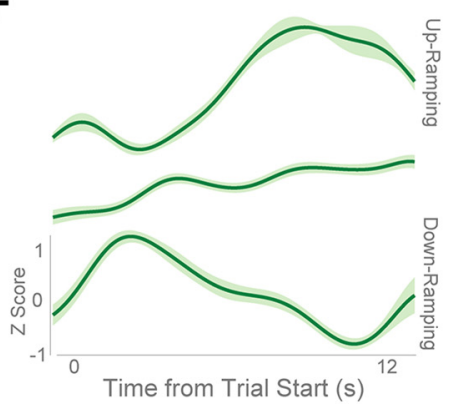

Figure 3. Time-related ramping activity of MFC and DMS neurons. $\boldsymbol{A}, \boldsymbol{B}$, Perievent rasters from MFC ( $\boldsymbol{A}$, blue) and DMS ( $\boldsymbol{B}$, green) neurons; light blue/green are FI3 trials, and dark blue/green are FI12 trials. Rasters are sorted by mean response time, with shorter mean response times on the top. During fixed-interval timing, both MFC and DMS neurons had time-related ramping, and this ramping activity appeared to scale on FI3 versus FI12 trials. We found evidence of both up-ramping (left) and down-ramping neurons (right) in the MFC and DMS. C, D, Heatmap of average z-scored perievent time histograms on FI12 trials from all MFC ( $\boldsymbol{C}$ and DMS (D) neurons. Red, Increased activity; blue, decreased activity. Histograms sorted by PC1. These heatmaps indicate that ramping activity was common among $77 \mathrm{MFC}$ and $89 \mathrm{DMS}$ neurons. $\boldsymbol{E}, \boldsymbol{F}$, Average neuronal activity in the $\operatorname{MFC}(\boldsymbol{E})$ and DMS $(\boldsymbol{F})$ sorted into neurons identified as up-ramping, nonramping, and down-ramping. Data from 77 neurons in 9 animals with MFC recordings and 89 neurons in 11 animals with DMS recordings. All data are from FI12 trials only. Variance is plotted as mean \pm SEM.

One important consideration during interval-timing tasks is that neuronal ramping activity could be primarily related to ongoing behavior. In our case, this activity would be related to lever pressing and would increase or decrease over time (Namboodiri and Hussain Shuler, 2014). Of note, some ramping neurons had no discernible lever-press-related modulations (Fig. 4A) while others had clear modulation around lever presses (Fig. 4B). We found that 29 of 77 MFC neurons (38\%) and 40 of 89 DMS neurons $(45 \%)$ had significant time-dependent ramping activity (i.e., a main effect of time on firing rate in our linear model; Fig. $4 C, D)$. By comparison, 17 of 77 MFC neurons (22\%) and 37 of 89 DMS neurons (41\%) had significant press modulation (i.e., significant changes in firing rate around lever press via a paired $t$ test;
Fig. $4 C, D)$. Many ramping neurons did not have significant leverpressing activity ( 21 of 29 , or $72 \%$ of ramping neurons in the MFC were not press-modulated and 18 of 40 , or $45 \%$ of ramping neurons in the DMS were not press-modulated), whereas some had both ramping and press-modulated activity (10\% in the MFC and 25\% in the DMS; Fig. 4C,D). These data imply that not all frontostriatal ramping activity can be explained by pressrelated activity during interval-timing tasks.

We also found that many DMS and MFC neurons appeared to multiplex both time and motor-related activity. For instance, in Figure $4 B$, press-related rasters sorted by the time in the interval revealed stronger press-related activity when the press occurred later in the interval (Fig. $4 B$, right). This pattern could be observed 
A
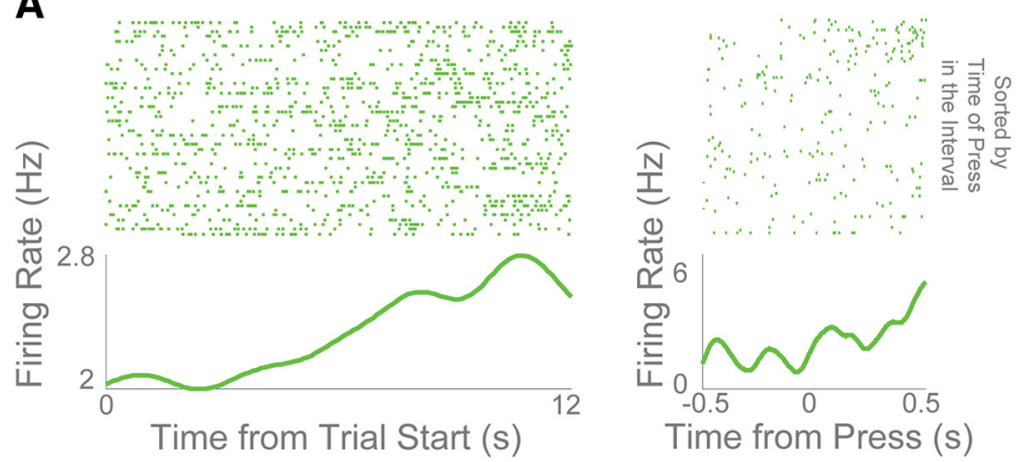

B
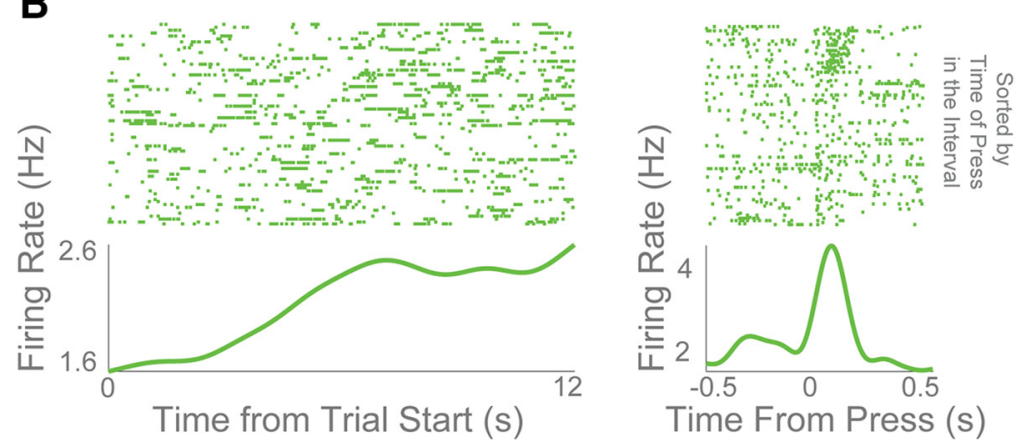

C

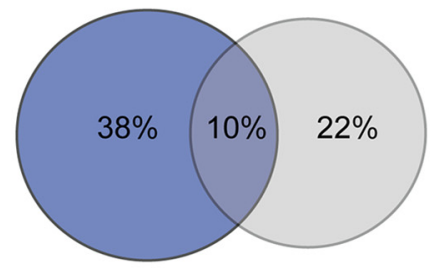

MFC Ramping MFC Press
D

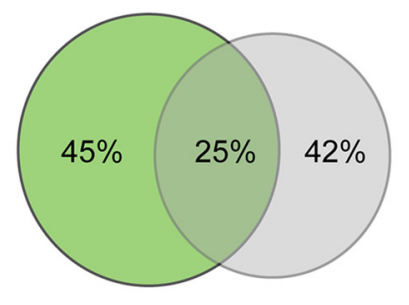

DMS Ramping DMS Press

Figure 4. Ramping activity of DMS neurons is not strictly motor. $A, D M S$ ramping neuron without obvious firing-rate modulation around lever press (at left, time 0 is trial start; at right, time 0 is lever press). B, By contrast, another DMS ramping neuron with clear lever-press-related activity. However, this neuron had different lever-press modulation depending on whether the lever was pressed early or late in the trial (rasters sorted by when the lever was pressed in the interval). C, D, Some neurons in the MFC ( $\boldsymbol{C}$ ) and DMS $(\boldsymbol{D})$ were ramping-modulated only (blue and green circles), some were press-modulated only (gray circles), and some were both ramping-modulated and press-modulated (overlap).

for press-modulated MFC and DMS neurons, some of which had very different patterns of activity depending on whether the lever presses occurred early or late in the interval (Fig. $5 A, B$ ). Notably, lever-press duration did not significantly change depending on the time in the interval that a press occurred $(p<0.45)$. We used a linear model to capture the effects of lever-press duration and the time in the interval the lever was pressed on each neuron's firing rate. Neurons with $p<0.05$ were considered significant. In the MFC, we found that $12 \%$ of neurons had a main effect of the time in the interval the lever was pressed, whereas the number of neurons with a main effect of lever-press duration (4\%) or interaction of time with press duration $(6 \%)$ was close to chance levels (Fig. $5 C, D$ ). In the DMS, we found that $17 \%$ of neurons had a main effect of the time in the interval the lever was pressed, 9\% had a main effect of lever-press duration, and 10\% had a significant interaction. These data compare neural activity linked to motor behaviors that occur at different times in the interval and indicate that even motor-related neuronal activity was affected by time.

A further way to explicitly factor out ramping and pressmodulated activity is to use a linear model to predict firing rate

over the entire session from either ramping (i.e., a monotonic linear function beginning at trial start) or lever pressing (i.e., this function is 1 when any lever press occurred, convolved with a Gaussian window). Accordingly, in both the MFC and DMS, ramping activity significantly fit the activity of more neurons than lever pressing (MFC: 51 neurons with press-related activity vs 72 with ramping activity, $\chi^{2}=17.8, p<$ 0.00005; DMS: 64 press-related neurons vs 74 with ramping, $\left.\chi^{2}=5.1, p<0.03\right)$. These data further imply that not all ramping activity can be explained by press-related activity during intervaltiming tasks.

As a final test, we evaluated whether ramping activity occurred in the absence of lever pressing. Specifically, we looked at neuronal activity during the first $4 \mathrm{~s}$ of FI12 trials where no responses occurred during the first 4-s epoch (Fig. 6A, $B$ ). Even though no presses occurred during this period, nine MFC ramping neurons (43\% of MFC ramping neurons and 12\% of total MFC neurons) showed ramping over the first $4 \mathrm{~s}$. By comparison, 15 DMS neurons (65\% of DMS ramping neurons, $17 \%$ of the total) showed ramping over this epoch.

In total, $21 \mathrm{MFC}$ neurons and $18 \mathrm{DMS}$ neurons had time-related ramping activity but no evidence of motor modulation. These analyses demonstrate that ramping activity among MFC and DMS neurons cannot be explained exclusively by pressrelated activity as (1) many ramping neurons were not significantly modulated by presses, (2) lever-press modulations were affected by when the lever was pressed during the interval, and (3) some neurons in MFC and DMS ramped over an epoch when no lever presses were made.

\section{Frontostriatal neuronal ensembles scale over time}

To further evaluate population activity in frontal and striatal ensembles, we turned to PCA, a data-driven technique that has been used extensively to describe multivariate neuronal ensemble datasets (Chapin and Nicolelis, 1999; Narayanan and Laubach, 2009a; Bekolay et al., 2014; Parker et al., 2014b, 2015b). The most common principal component, PC1, explained $65 \%$ of variance on FI3 trials and $47 \%$ of variance on FI12 trials (Fig. $7 A, B$ ), and PC2 explained $31 \%$ of variance on FI3 trials and $25 \%$ on $\mathrm{FI} 12$ trials (Fig. $7 A, B$ ).

Many MFC and DMS ramping neurons had similar activity profiles on FI3 and FI12 trials, yet appeared to adjust their slope based on the interval being timed. In other words, the neurons appeared to "scale" (i.e., stretch or compress) their activity based on the delay associated with the cue presented within a trial (Fig. $3 A, B$; Stokes et al., 2013). To evaluate whether this effect held across the population (i.e., including ramping, nonramping, and lever-press-modulated neurons), we rebinned data from all neu- 


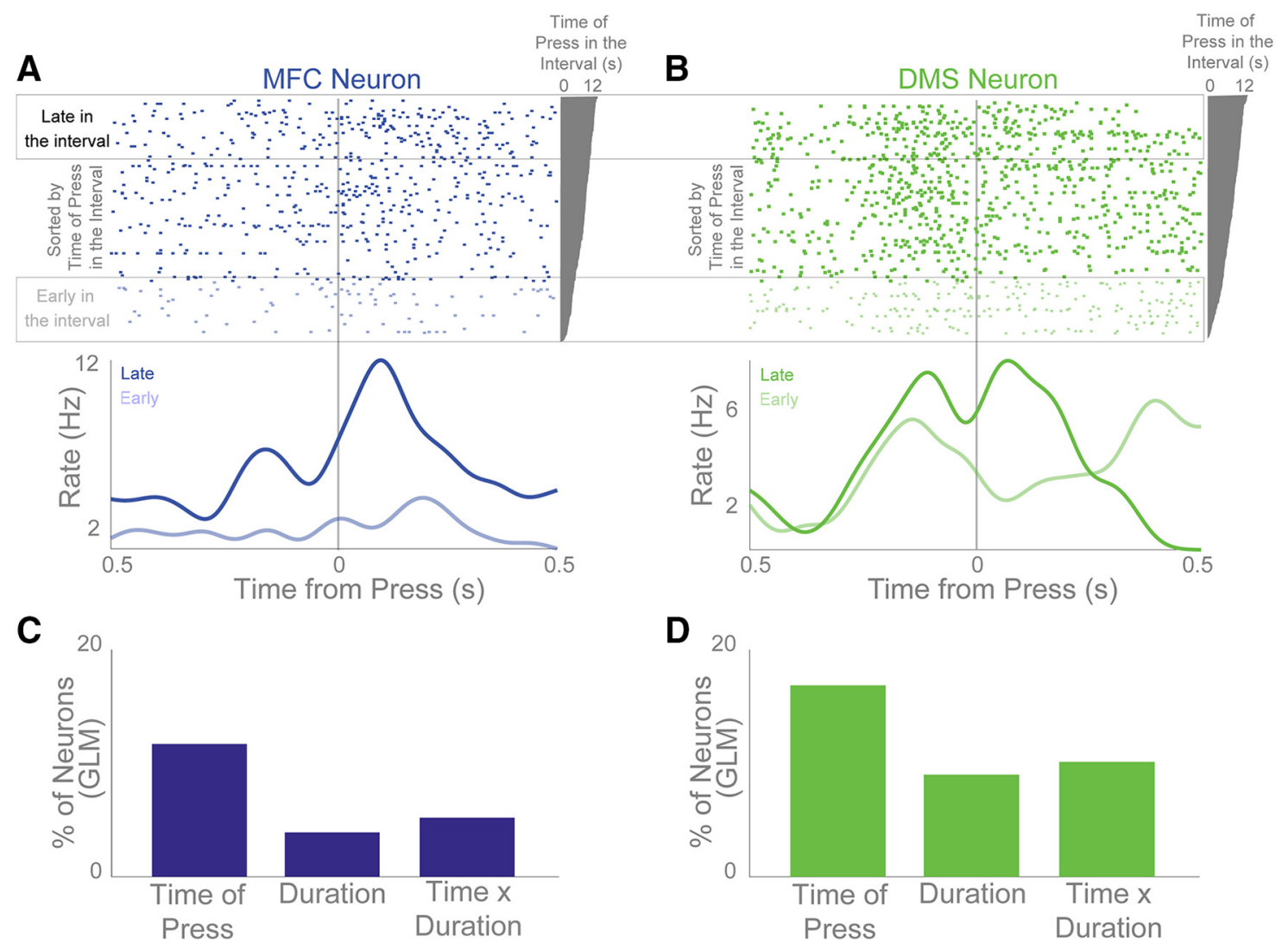

Figure 5. Motor activity varies with time. $\boldsymbol{A}, \boldsymbol{B}, \operatorname{MFC}(\boldsymbol{A})$ and $\operatorname{DMS}(\boldsymbol{B})$ press-modulated neurons that show changes in activity with time in the interval on Fl12 trials. Rasters are plotted from early in the interval (bottom) to late in the interval (top). Dark blue/green trace shows press events late in the interval while light blue/green shows press events early in the interval. $\boldsymbol{C}, \boldsymbol{D}$, Percentage of neurons in the MFC $(\boldsymbol{C})$ and DMS (D) that had a significant linear fit of time of press in the interval, significant duration of lever press, or a significant interaction between time of press and duration of press.

rons in proportion to the duration associated with a given trial type (0.1-s bins for FI3 trials, and 0.4-s bins for FI12 trials; Fig. $7 E, F)$. Thus, bin widths across FI3 and FI12 trials now contained data corresponding to equivalent proportions of the interval being timed during a trial. Consistent with population activity scaling across trial types, we found that principal components during FI3 and FI12 trials overlapped in scaled time and that MFC and DMS ensembles had similar trajectories in principal component space (Fig. $7 E, F$ ). Notably, scaling was also apparent for PC2 in addition to PC1, suggesting that scaling is not only confined to ramping activity. These data suggest that, in both areas, ensemble activity followed a similar trajectory on FI3 and FI12 trials that differed by a scalar factor proportional to the timed interval (Mello et al., 2015).

To confirm this effect on neuronal firing rates across our MFC and DMS ensembles, we computed the speed of MFC and DMS ensemble trajectories during FI3 and FI12 trials across time in high-dimensional space, where each neuron is a dimension and firing rate determines the value on each axis (Stokes et al., 2013). If ensemble activity scales with the interval being timed, these trajectories should traverse state-space faster during FI3 trials than during FI12 trials when evaluated with respect to absolute time. However, when evaluated with respect to scaled time (i.e., speed as a function of successive proportions of the interval that have elapsed), the speed of either trajectory should be equivalent. Consistent with this prediction, the ratio of trajectory speed between FI3 and FI12 trials was 4:1 when evaluated in absolute time (Fig. 7G,H, MFC and DMS, respectively; bands represent 95\% confidence intervals). Of note, the FI3/F12 speed ratio for the first one-third of each trial was 4:1 even when comparing trials in which there were no lever presses during this epoch $(p<0.23)$. Taken together, these data demonstrate that neuronal ensembles scaled to represent elapsed time in MFC and DMS.

\section{Frontostriatal neuronal ensembles encode time}

To evaluate whether frontal and striatal ensembles contained temporal information, we used Naive Bayesian classifiers (NBCs) to decode time within a trial from frontostriatal activity (Fig. 8A). Firing rates from each neuron on each trial were binned using a sliding window (50-ms width, 25-ms spacing). Then, using leaveone-out cross-validation, we evaluated whether time within a trial could be decoded from population activity (Fig. $8 B-G$ ). To quantify classifier performance, we used the sum of squared errors (SSE) between predicted and actual time within a trial. This analysis revealed that time could be decoded from both MFC and DMS ensembles relative to shuffled data $\left(\mathrm{MFC}_{(67)}=8.7, p<\right.$ 0.000001 ; DMS $t_{(67)}=7.6, p<0.00001$; Fig. $8 H$; Table 1$)$. Both MFC and DMS neuronal ensembles predicted time over the first $4 \mathrm{~s}$ of FI12 trials even when no responses occurred during this epoch, showing that ensemble predictions of time could not be explained by press-related activity alone (DMS vs shuffled data, $t_{(67)}=5.64, p<0.00001$; MFC vs shuffled data, $t_{(75)}=2.37, p<$ $0.05)$. Furthermore, neuronal ensembles containing only ramping neurons performed better than ensembles containing only nonramping neurons (MFC: $t_{(67)}=5.9, p<0.00001$; DMS: $t_{(67)}=2.7, p<0.01$; Fig. $8 B-H$; Table 1$)$. Taken together, these data provide evidence that frontal and striatal ensembles encode 


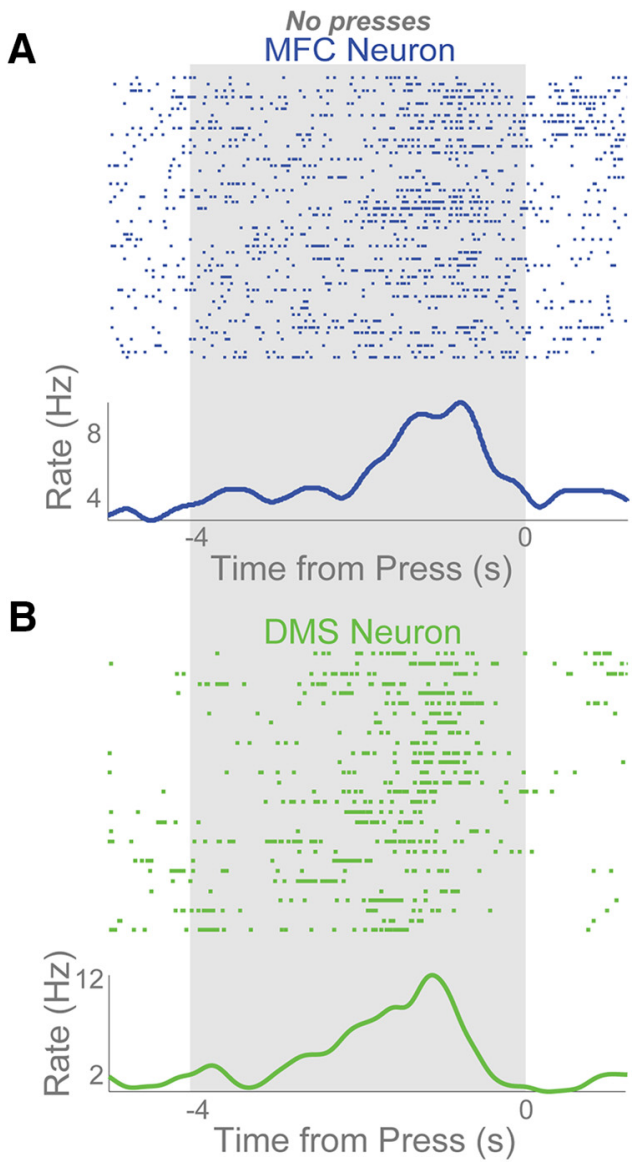

Figure 6. Ramping activity before movement. $\boldsymbol{A}, \boldsymbol{B}$, Perievent rasters of ramping neurons from MFC $(\boldsymbol{A})$ and DMS $(\boldsymbol{B})$ in the $4 \mathrm{~s}$ before the first press event of a trial. The time of the first press on a trial is 0 with rasters being plotted in the $4 \mathrm{~s}$ before the press. The gray area shows time where no presses were occurring.

temporal information and that ramping is a key temporal signal among frontostriatal ensembles.

\section{Striatal ramping neurons are more correlated with MFC activity than nonramping neurons}

To investigate the relationship between MFC and DMS activity, we recorded simultaneously from 40 MFC neurons and 32 DMS MSNs in five animals. This sample, although unbiased, represents only a small fraction of the neurons in each brain area. Thus, we did not find any evidence of synaptically-connected pairs. However, we noticed that over the interval, MFC and DMS neurons' firing rates covaried. Across simultaneously-recorded pairs of MFC and DMS neurons, 24\% of MFC-DMS pairs composed of ramping neurons had significant trial-by-trial correlations ( 6 of 25 ramping pairs; Fig. 9A). Of note, we used partial correlation to compare trial-by-trial firing rates of MFC and DMS neurons while controlling for the behavioral variance of the number of responses. More ramping pairs had significant trial-bytrial correlations than nonramping pairs (24\% of ramping pairs vs $7 \%$, or 9 of 121 , nonramping pairs; $\chi^{2}=6.2, p<0.01$; Fig. $9 A$ ). Few correlations were observed between ramping and nonramping pairs ( 21 of 223 in the MFC, or 9\%; 17 of 173 in DMS, or $10 \%$; Fig. 9A). These data demonstrate that ramping neurons in MFC and DMS had particularly strong trial-by-trial correlations.

To analyze the temporal evolution of MFC and DMS correlations, we turned to joint peristimulus time histograms (JPSTHs) (Aertsen and Gerstein, 1985; Narayanan and Laubach, 2009b).
The JPSTH matrix is compared with a trial-shuffled matrix with firing-rate modulations preserved but trial-by-trial relationships destroyed. As such, this technique captures functional interactions between two neurons while correcting for firing-rate modulations. Using this technique on FI12 trials, we found that functional correlations between MFC and DMS neurons had marked changes over the interval (Fig. 9B). Across 25 simultaneously-recorded MFCDMS ramping pairs, we observed a pattern of JPSTH interactions that was specifically elevated for ramping neurons early in the inter$\mathrm{val}$ (ramping vs nonramping: first 4 s of the interval: $t_{(123)}=2.6, p<$ 0.01 ; middle 4 s: $t_{(123)}=1.1, p<0.26$; last 4 s: $t_{(123)}=0.66, p<0.43$; Fig. 9C).

As noted above, lever pressing is a critical consideration in our analyses, although we note that the pattern of JPSTH interactions is time-varying but quite distinct from the time of lever pressing in Figure $1 B$. To further correct for responses, particularly shortlatency presses that can disproportionately affect JSPTH interactions, we generated press-corrected JSPTHs by subtracting each press on each trial from MFC and DMS firing rates and calculating the JPSTH of the residuals. We found a similar time-varying pattern of JPSTH interactions (Fig. 9D), and a similar elevation of JPSTH interactions early in the interval (ramping vs nonramping: first 4 s of the interval: $t_{(123)}=2.9, p<0.005$; middle $4 \mathrm{~s}$; $t_{(123)}=1.0$, $p<0.32$; last 4 s: $t_{(123)}=0.03, p<0.97$; Fig. $\left.9 D\right)$. These data indicate that JPSTH interactions between ramping neurons could not be accounted for by lever pressing alone.

Finally, these JPSTH interactions were strongest when using 1 -s bins, suggesting that these interactions were slow and not monosynaptic (Fig. 9E). Together, these data indicate that ramping MFC-DMS neurons had particularly strong functional connectivity when compared with nonramping populations of neurons and that ramping may represent a motif for frontostriatal interactions during interval timing.

\section{Spectral activity in frontostriatal circuits during interval timing}

Our recent work has established that there are prominent lowfrequency oscillations of $\sim 4 \mathrm{~Hz}$ during interval-timing taskshere, we observed these oscillations in both MFC and DMS (Fig. $10 A, B$; Emmons et al., 2016). There was prominent $\sim 4-\mathrm{Hz}$ phase-coherence around cue onset in both MFC and DMS neurons (Fig. 10C). These data suggest that the MFC might exert top-down control over DMS networks via $\sim 4$-Hz activity. Recent work has indicated that MFC $\sim 4-\mathrm{Hz}$ activity can synchronize single neurons involved in cognitive processing, even across areas (Narayanan et al., 2013; Parker et al., 2014b; Dejean et al., 2016). Consistent with these results, we found that single MSNs appeared to fire in phase with MFC LFPs primarily around cue onset (Fig. 10D). Importantly, only ramping MSNs had cue-triggered coupling with MFC LFPs (ramping vs nonramping MFC-DMS cross-spikefield 4-Hz coherence: $t_{(40)}=2.6, p<0.01$; Fig. $\left.10 E, F\right)$. These data are an example of cross-area $4-\mathrm{Hz}$ spike-field coherence in frontostriatal circuits. Further, they provide evidence that ramping MSNs specifically have cross-area coupling with cue-triggered MFC 4-Hz activity (Narayanan et al., 2006; Allen et al., 2008; Parker et al., 2014b). This finding is consistent with the "starting gun" proposed by computational models of timing and implies that timing signals can be reset/initiated by $\sim 4-\mathrm{Hz}$ MFC activity in frontostriatal circuits (Buhusi and Meck, 2005).

\section{MFC inactivation attenuates DMS ramping activity}

Our data thus far suggest that ramping activity is ubiquitous among frontostriatal networks and is particularly correlated 
A

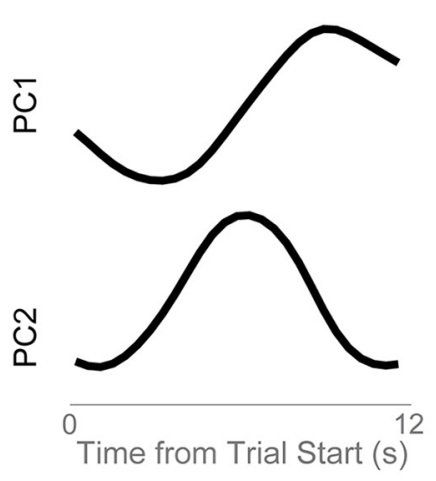

C

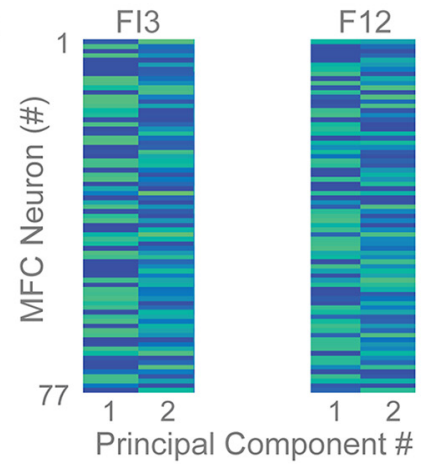

$\mathbf{E}$
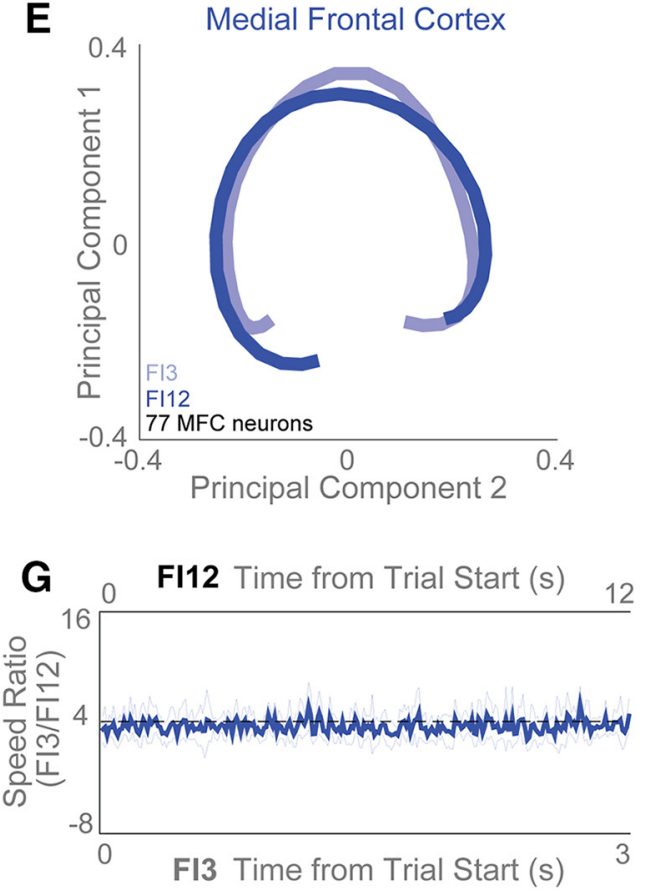
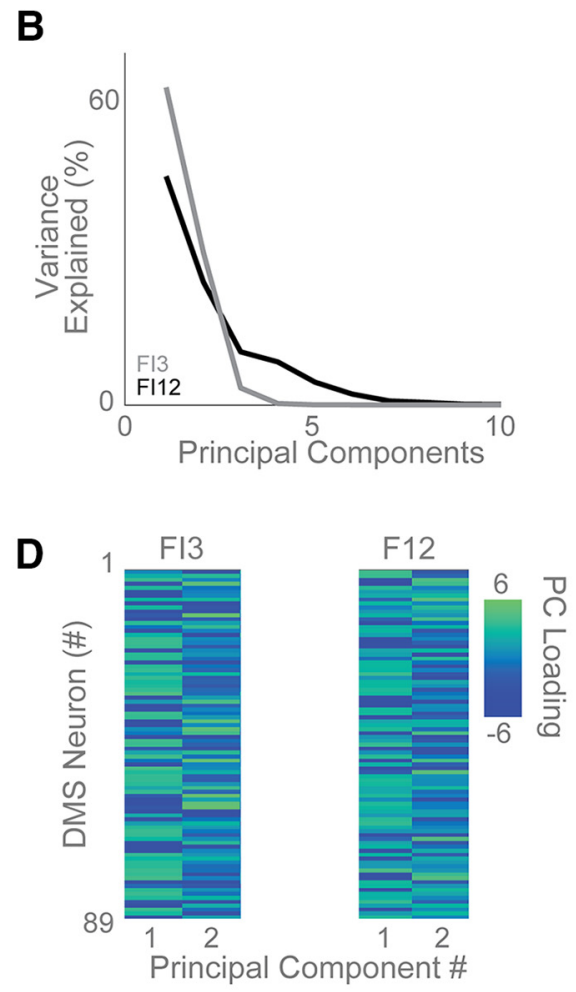

$\mathbf{F}$
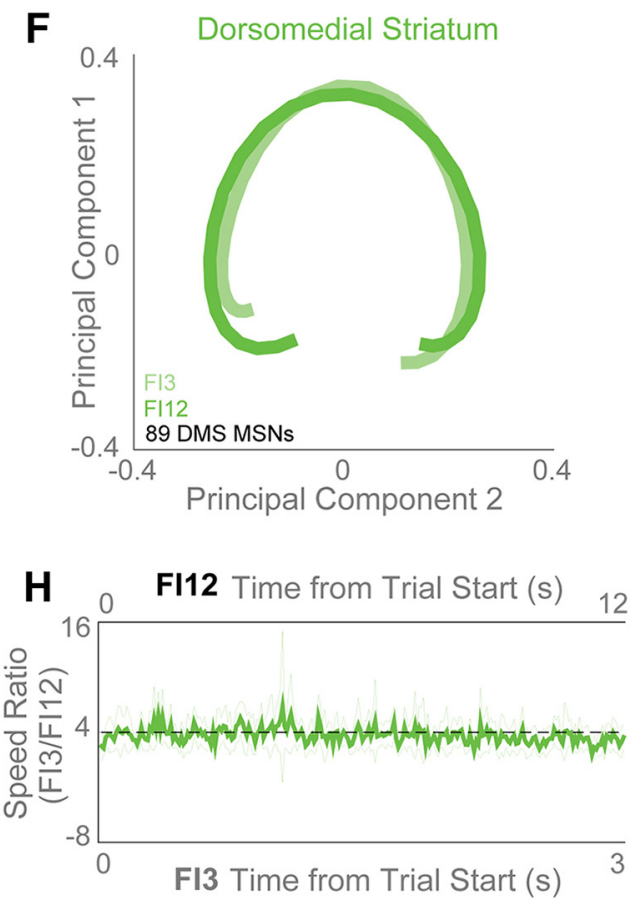

Figure 7. Frontostriatal ensembles scale proportionally at different intervals. $\boldsymbol{A}, \boldsymbol{B}$, Data-driven principal component analysis (PCA) $(\boldsymbol{A})$ revealed that ramping activity is the most common principal component ( $P C 1$ ) across frontostriatal ensembles and $(\boldsymbol{B})$ explained $>40 \%$ of variance on Fl3 (gray) and $>60 \%$ of variance on Fl12 (black) trials. $C, D$, The strength of loading of $P C 1$ and $\mathrm{PC} 2$ are shown for all MFC $(\boldsymbol{C})$ and DMS $(\boldsymbol{D})$ neurons. $\boldsymbol{E}, \boldsymbol{F}, \mathrm{PC}$ looked remarkably similar for FI3 and FI12 trials for $(\boldsymbol{E}) \mathrm{MFC}$ and $(\boldsymbol{F})$ DMS neurons. $\boldsymbol{G}, \boldsymbol{H}$, To quantify the scaling across the entire MFC and DMS ensembles, we examined the speed that neuronal ensemble activity moved in high-dimensional space for FI12 and Fl3 trials. We found that the speed was proportional to the interval (ratio of $\mathrm{FI} 12 / \mathrm{Fl} 3$, or 4:1) for the MFC (G) and DMS $(\boldsymbol{H})$. Confidence intervals shown in light blue/green.

among MFC and DMS neuronal ensembles. If ramping activity in the DMS depends on MFC input, then disrupting the MFC should attenuate ramping activity. We tested this idea by inactivating the MFC using the $\mathrm{GABA}_{\mathrm{A}}$ agonist muscimol, a technique we have used in the past to reversibly inactivate MFC networks (Narayanan et al., 2006; Allen et al., 2008; Parker et al., 2014b).
As in past work, MFC inactivation markedly changed the temporal control of responding (Narayanan and Laubach, 2006; Kim et al., 2009; Narayanan et al., 2012; Xu et al., 2014; Fig. 11A). We found similar deficits in interval timing with MFC inactivation as characterized by several measures of timing, including response efficiency $\left(14 \pm 1 \%\right.$ with saline vs $9 \pm 2 \%$ with muscimol; $t_{(10)}=$ 

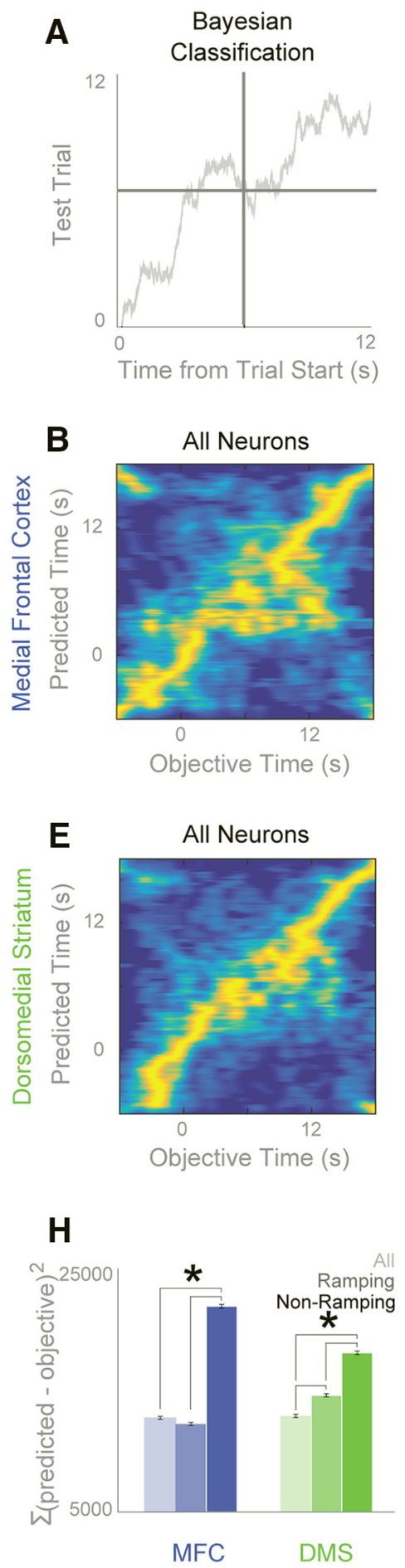
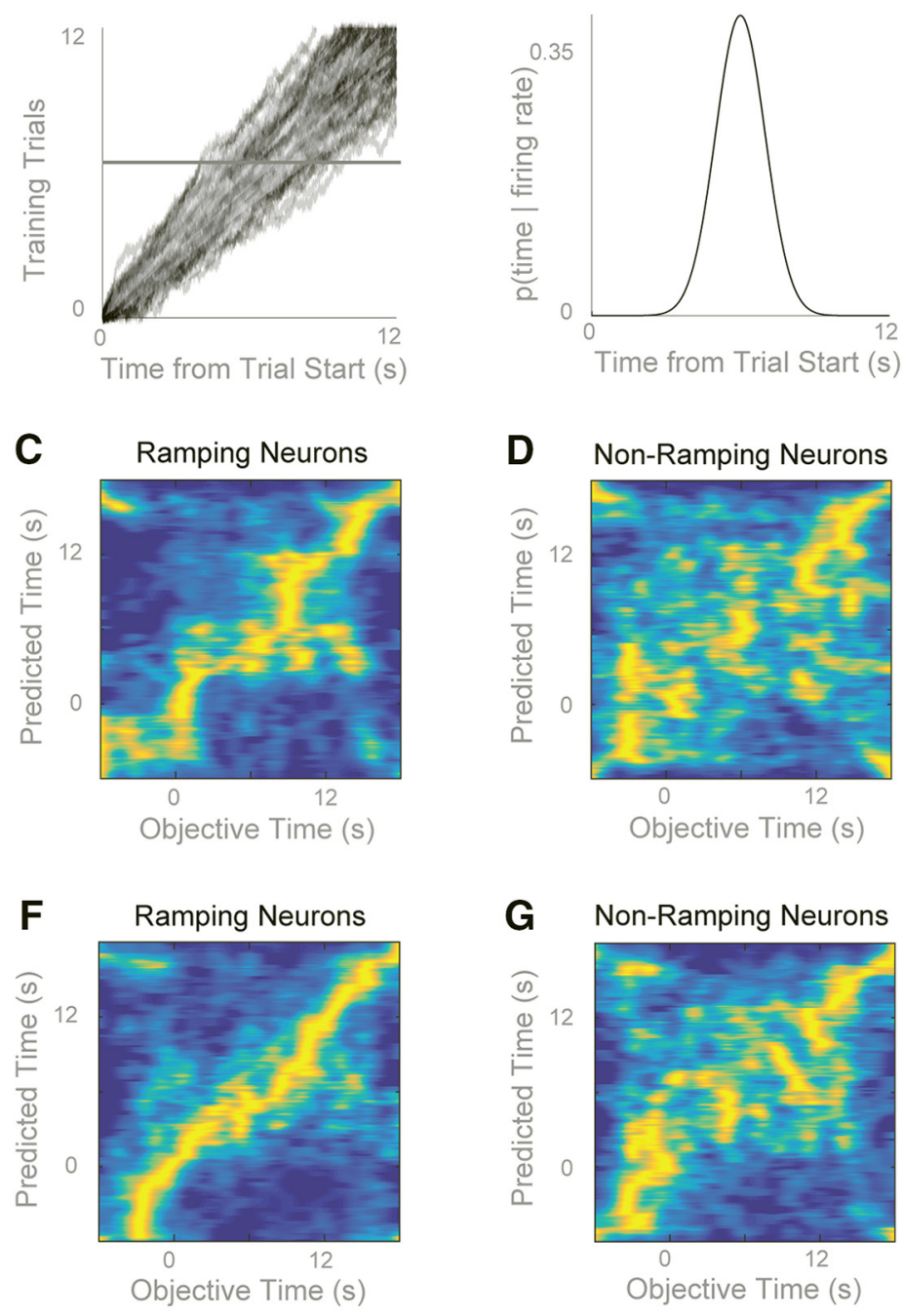
Table 1. Classification statistics

\begin{tabular}{lrrr}
\hline & \multicolumn{1}{c}{} & df & $\begin{array}{r}\text { Significance } \\
\text { (two-tailed) }\end{array}$ \\
\hline Paired samples test & & & \\
$\quad$ Pair 1: Striatal shuffled-Striatal all & 7.546 & 67 & 0.000 \\
Pair 2: Striatal all-Striatal ramping & -2.086 & 67 & 0.041 \\
Pair 3: Striatal all-Striatal nonramping & -5.234 & 67 & 0.000 \\
$\quad$ Pair 4: Striatal ramping-Striatal nonramping & -2.650 & 67 & 0.010 \\
Paired samples test & & & \\
Pair 1: MFC shuffled-MFC all & 8.699 & 67 & 0.000 \\
Pair 2: MFC all-MFC ramping & 0.705 & 67 & 0.483 \\
Pair 3: MFC all-MFC nonramping & -7.056 & 67 & 0.000 \\
Pair 4: MFC ramping-MFC nonramping & -5.876 & 67 & 0.000 \\
\hline
\end{tabular}

Within condition comparisons: Striatum: All versus Ramping, paired $t_{(67)}=-2.086, p<0.05$; All versus Nonramping, paired $t_{(67)}=-5.234, p<0.001$; Ramping versus Nonramping, paired $t_{(67)}=-2.650, p<0.02$; MFC: All versus Ramping, paired $t_{(67)}=0.705, p>0.4$; All versus Nonramping, paired $t_{(67)}=-7.056, p<0.001$; Ramping versus Nonramping, paired $t_{(67)}=-5.876, p<0.001$.

(Narayanan and Laubach, 2006, 2008). In line with this, video analysis suggested that MFC inactivation did not grossly change overt motor behaviors. There was no difference in lever-approach behavior in sessions with the MFC active (saline infusion) versus MFC inactive (muscimol infusion; based on hand-coded scores of two raters; $p=0.9$; Fig. $11 D$ ). Classification of video data using NBCs performed at chance in comparing saline and muscimol sessions. Finally, there was also no difference in leverpress duration $(0.5 \pm 0.06 \mathrm{~s}$ vs $0.6 \pm 0.02 \mathrm{~s} ; p=0.13$; Fig. $11 E)$. These data are consistent with our prior work in showing that MFC inactivation does not change the motor component of lever presses or other aspects of operant behavior that we could measure (Narayanan and Laubach, 2006; Narayanan et al., 2006, 2012, 2013; Parker et al., 2014a, 2017).

Next, we examined how MFC inactivation affected the activity of DMS MSNs. In six rats, we recorded from 49 MSNs in control sessions and $41 \mathrm{MSN}$ in sessions with MFC inactivation. MFC inactivation did not change the number of DMS MSNs with press-related activity (45 vs $42 \%$ for press-modulated cells for MFC active vs MFC inactive sessions, respectively; Fig. 11F).

Critically, MFC inactivation decreased ramping activity. We found 22 ramping DMS neurons (46\%) in sessions with MFC active versus 8 DMS neurons (20\%) in sessions with MFC inactive $\left(\chi^{2}=6.1, p<0.01\right.$; Fig. $\left.11 G\right)$. Note that this analysis was not driven by any differences in response rate as we matched trials from sessions with MFC active to the middle tertile of response times from sessions with MFC inactive and only included trials with response times that fell within this interval (6.9-10 s; Parker et al., 2014b). When ramping neurons with motor activity were excluded, there was still a decrease in ramping activity in sessions with MFC inactive (14 MSN ramping neurons with MFC active vs 3 with MFC inactive; $\chi^{2}=5.7, p<0.02$ ).

To further control for potential differences in lever pressing, we used a repeated-measures analysis to investigate how DMS MSN press-related activity $(0-0.5 \mathrm{~s}$ after each lever press, as in Fig. 5) changed as a function of MFC inactivation and the time the lever press occurred in the interval, controlling for neuron-specific variance (sessions with MFC active vs MFC inactive were treated as independent). This analysis allowed us to evaluate time-related firing-rate changes while rats were engaging in the same behavior (i.e., pressing) during a trial. As in Figure 5, we found significant main effects of MFC inactivation and the time the press occurred in the interval (Table 2; linear models of press-related firing had a significant slope of firing rate vs time while controlling for neuronspecific variance; $p<10^{-8}$ ). There was a significant interac-
A
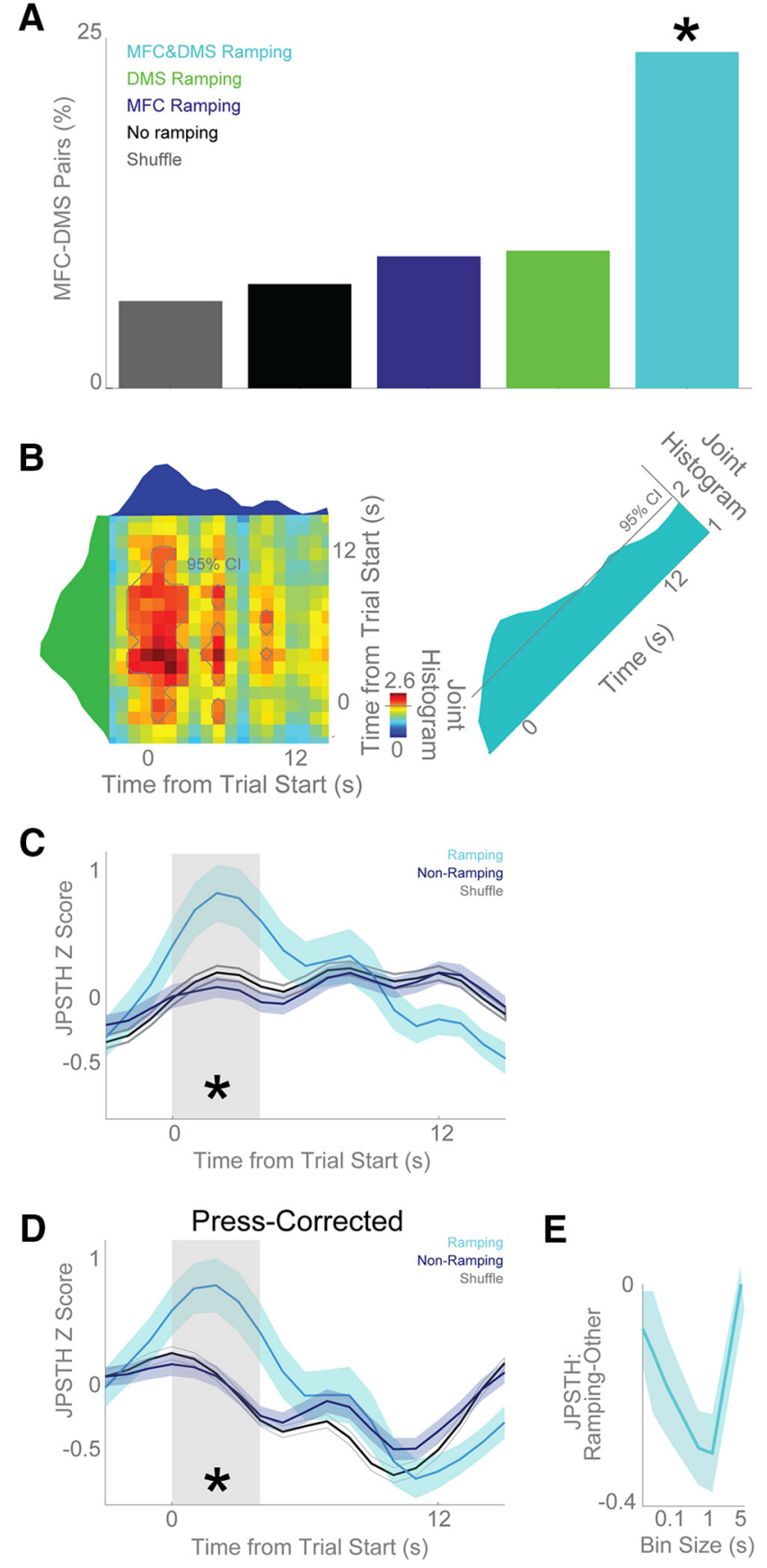

Figure 9. MFC and DMS neurons are correlated in time. $\boldsymbol{A}$, Trial-by-trial correlation revealed that pairs of neurons where both neurons ramped (MFC\&DMS Ramping, cyan) were much more likely to have a significant interaction than pairs of neurons where only one neuron ramped (DMS Ramping, green, and MFC Ramping, blue), where neither ramped (No Ramping, black), or compared with shuffled data (Shuffle, gray). $\boldsymbol{B}$, To examine the time evolution of functional interactions between MFC and DMS neurons across the interval, we turned to JPSTHs, which look at trial-by-trial, bin-by-bin interactions corrected for firing rate. MFC and DMS neurons could have JPSTH interactions. For this pair, 95\% confidence intervals based on shuffled data are plotted in light gray lines. C, JPSTH interactions during the interval for ramping neurons (cyan), nonramping neurons (blue), or shuffled data (gray). Data from 337 pairs of 40 MFC neurons and 42 DMS neurons in five animals with simultaneous recordings. Early in the interval (i.e., $0-4 \mathrm{~s}$; shaded gray area), ramping neurons had stronger JPSTH interactions than nonramping neurons. $\boldsymbol{D}$, Lever pressing is a key consideration that could affect JPSTH interactions; to correct for this, we subtracted lever presses on each trial from MFC and DMS firing rates, and calculated press-corrected JPSTHs on the residuals. For press-corrected JPSTHs, there were still stronger interactions for ramping neurons compared with nonramping neurons early in the interval. $\boldsymbol{E}$, JPSTH interactions with different bin sizes showing that interactions were maximal at 1-s bins. All data are mean \pm SEM; ${ }^{*} p<0.05$. 
A
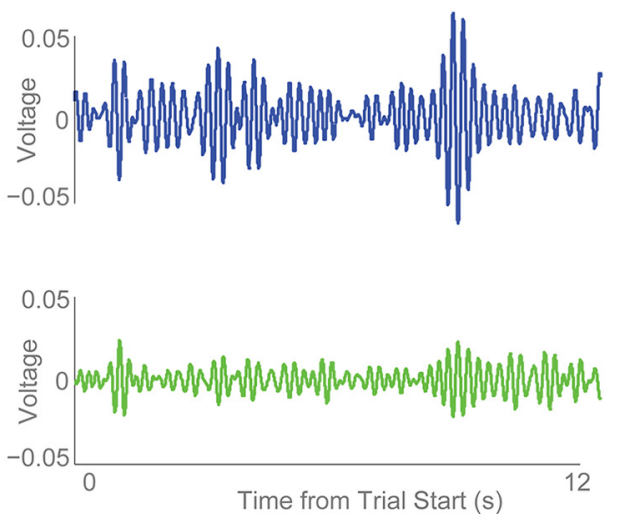

B

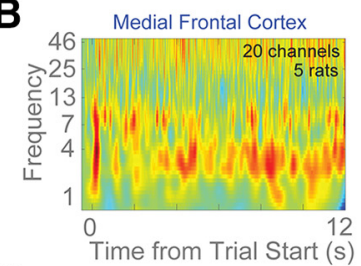

C

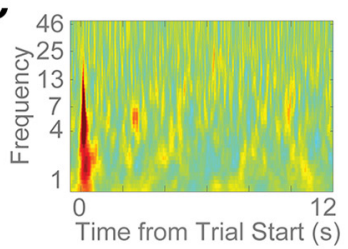

D

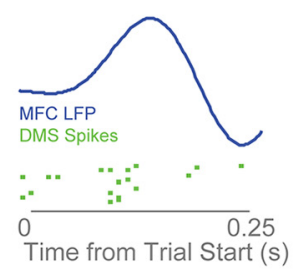

$\mathbf{F}$
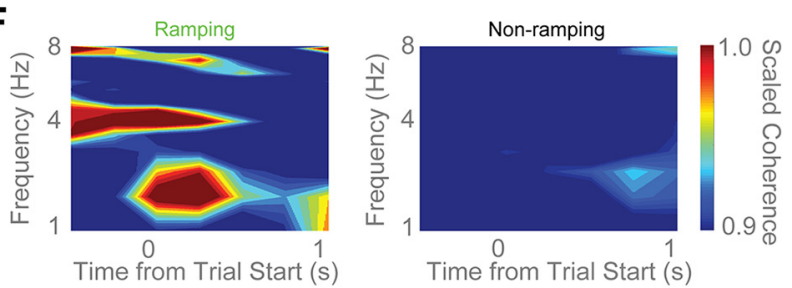

Figure 10. DMS MSNs are functionally coupled with cue-evoked MFC 4-Hz activity. A, Raw field potentials from the MFC (blue) and DMS (green) filtered from 3 to $6 \mathrm{~Hz}$ revealed marked modulations after the stimulus and before response preparation. Average LFP activity from one animal with simultaneous MFC and DMS recordings is shown. $\boldsymbol{B}$, Time-frequency analyses reveal strong $\sim 4$-Hz cue-triggered power in both MFC and DMS neurons. Red, Increased power; blue, decreased power. $\boldsymbol{C}$, Intertrial coherence is observed in both MFC and DMS neurons at low frequencies. Red, strong phase-locking across trials; blue, weak phase-locking across trials. $\boldsymbol{D}$, To test this idea, we examined DMS MSN spiking activity in relation to MFC LFPs, and found instances of DMS neuronal firing that was coupled to $\sim 4-\mathrm{Hz}$ rhythms. $\boldsymbol{E}$, 0 n average, ramping MSNs had more spike-field coherence in delta bands $(1-4 \mathrm{~Hz})$ than nonramping neurons. Coherence is normalized to each neuron's $95 \%$ confidence interval to facilitate comparisons across neurons. Red, significant coherence. $\boldsymbol{F}$, This coupling was apparent for ramping (left) but not for nonramping (right) MSNs in the delta but not theta range. Data from 42 DMS MSNs in five animals with simultaneous MFC LFP recordings. All data are mean $\pm \mathrm{SEM}$; ${ }^{*} p<0.05$.

tion between MFC inactivation and the time the lever press occurred in the interval ( $p<0.00003$; Table 2), implying that across neurons, MFC inactivation changed time-dependent DMS MSN press-related activity. That is, MFC activity differ- entially affected how DMS MSN press-related activity occurred at different times during the interval.

There were no overall differences in firing rate of DMS neurons over the interval with MFC inactivation (Fig. 11I).

\section{Discussion}

We studied information processing in frontostriatal circuits during a fixed-interval timing task in rodents. We report four major findings. First, ramping patterns of neuronal activity were prominent among MFC and DMS neuronal ensembles. Second, ramping neurons within these ensembles encoded time and frontostriatal neuronal ensemble activity scaled across different intervals. Third, MFC ramping activity and cue-triggered $\sim 4$ - $\mathrm{Hz}$ activity were more correlated with DMS ramping than with nonramping activity. Finally, MFC inactivation specifically attenuated ramping activity in the DMS and decreased intervalrelated firing of MSN neurons. These data suggest that striatal neurons integrate the activity of frontal neurons that accumulate temporal evidence data, conferring a novel view of frontostriatal interactions and illuminating how frontal circuits exert topdown control of striatal MSNs to guide the timing of action.

\section{Ramping and drift-diffusion models}

Our data provide evidence that drift-diffusion models (DDMs) govern frontostriatal interactions. While such DDM interactions have been shown rather extensively in "bottom-up" contexts where cortical neurons are integrating sensory evidence (Gold and Shadlen, 2007), in top-down contexts prefrontal inputs can bias the drift rate of DDMs (Philiastides et al., 2011; Cavanagh and Frank, 2014). To our knowledge, DDMs have not been traditionally applied to frontostriatal interactions. Our results indicate that ramping MFC and DMS neurons interact during interval timing. These interactions were not monosynaptic in our data, but might indicate that the MFC and DMS neurons that we randomly sampled are within the same functional circuit. Without MFC input, we found that DMS ramping was attenuated and that MFC inactivation decreased the firing rate of MSNs, consistent with a loss of glutamatergic corticostriatal input (Wall et al., 2013). These data are broadly consistent with prior applications of DDMs to cortical activity (Durstewitz, 2003; Simen et al., 2011; Merchant and Averbeck, 2017) and help illustrate informationprocessing principles in frontostriatal circuits during interval timing.

Ramping patterns have been reported previously in MFC and striatal networks (Matell et al., 2003; Narayanan and Laubach, 2009a; Merchant et al., 2013; Parker et al., 2014b, 2017; Donnelly et al., 2015; Gouvea et al., 2015; Bakhurin et al., 2017; Kim et al., 2017). Our work here extends these prior studies by demonstrating that time-dependent frontostriatal ramping signals are correlated and that DMS ramping depends on MFC function. These data are distinct from previous work that has, in different contexts, suggested that the striatum can serve as a "teaching signal" to the frontal cortex (Pasupathy and Miller, 2005; Histed et al., 2009) and encodes specific actions (Ma et al., 2014a, 2014b). Rather, our data suggest that striatal ramping is reflective of and dependent upon MFC activity.

Notably, in the DMS, temporal encoding from all neurons performed better than ramping neurons alone (Fig. $8 \mathrm{H}$ ), indicating that there may be some auxiliary temporal signal in the DMS. Furthermore, the activity we find in this manuscript is not strictly monotonic as in DDMs (Matell and Meck, 2004; Simen et al., 2011). Relatedly, finding a significant linear trend does not exclude other patterns of activity in frontostriatal ensembles. MFC-DMS interac- 
A

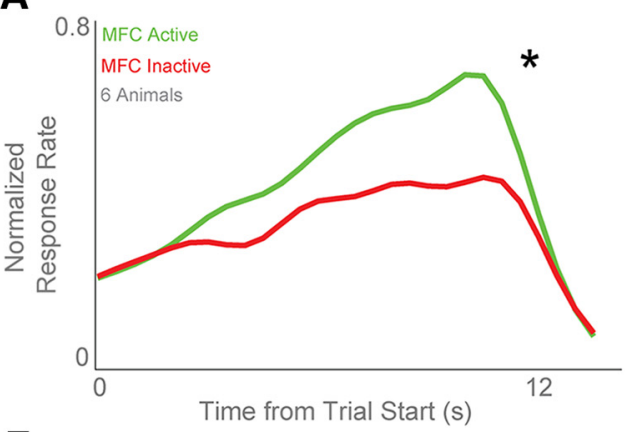

F
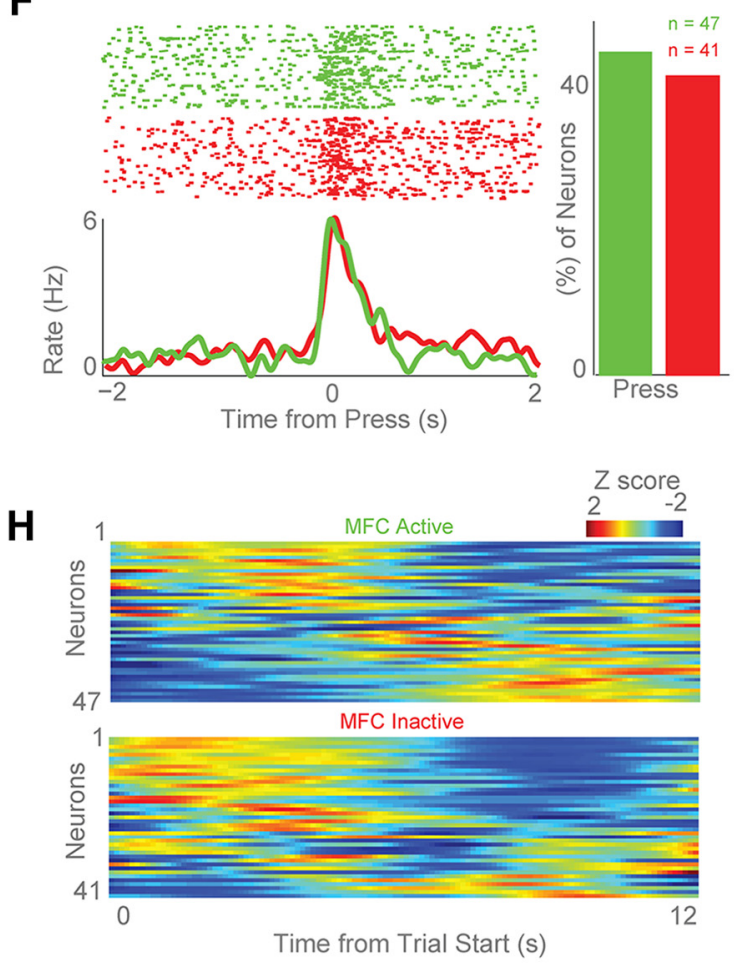

B

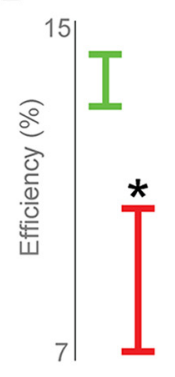

C

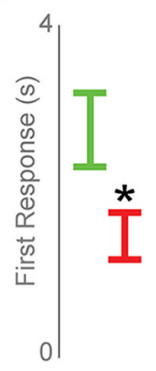

D

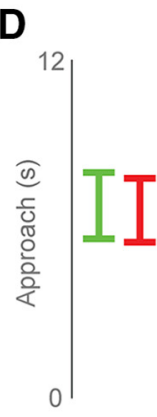

E

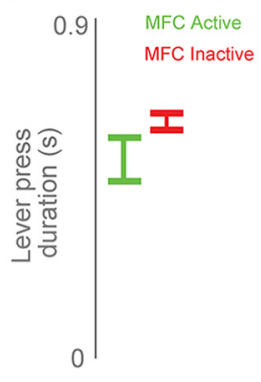

G

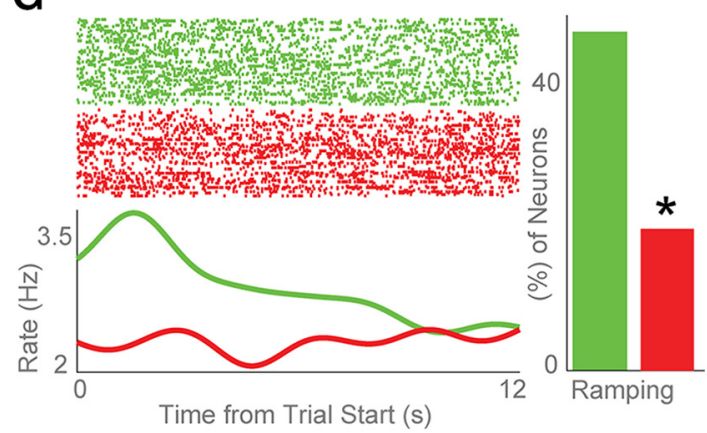

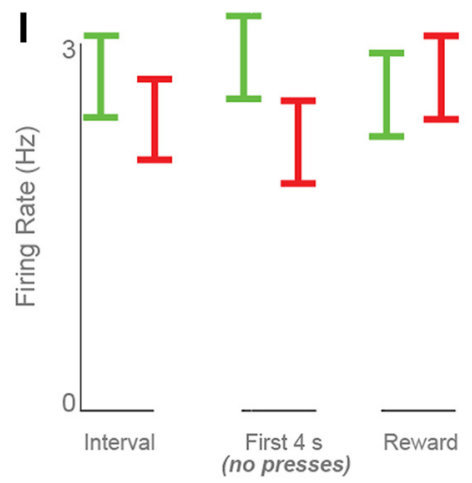

Figure 11. MFC inactivation attenuates ramping in the striatum. We inactivated the MFC with muscimol in six animals. $\boldsymbol{A}-\boldsymbol{C}$, In line with our prior work, MFC inactivation ( $\boldsymbol{A}$; green, MFC active; red, MFC inactive) impaired interval timing by $(\boldsymbol{B})$ decreasing the efficiency of timed responses compared with saline infusions and by $(\boldsymbol{C})$ decreasing the time of the first response (Narayanan et al., 2012; Parker et al., 2014a). D, The time the animals approached the lever (as coded by two human raters) did not change for MFC active (saline infusion) versus MFC inactive (muscimol infusion) sessions. $\boldsymbol{E}$, The duration of each lever press also did not change for MFC active versus MFC inactive sessions. $\boldsymbol{F}$, MFC inactivation did not change lever-press-modulated neurons. $\boldsymbol{G}, \boldsymbol{H}$, However, MFC inactivation significantly attenuated ramping activity among DMS neuronal ensembles $(\boldsymbol{G})$, and changed the temporal pattern of neural activity across the interval $(\boldsymbol{H})$. Data from 47 MSNs in six animals with MFC active (saline) and 41 MSN recorded in the same six animals with MFC inactive (muscimol). I, MFC inactivation did not significantly reduce MSN firing around reward events (right). All data are mean $\pm S E M ;{ }^{*} p<0.05$.

Table 2. Repeated-measures ANOVA

\begin{tabular}{lcl}
\hline & $F$ & Significance \\
\hline Time & 28.1 & $1.20 \mathrm{e}-07$ \\
Condition & 6.7 & 0.00942 \\
Time * Condition & 17.6 & $2.83 \mathrm{e}-05$ \\
\hline
\end{tabular}

Model: Firing rate $\sim$ Time ${ }^{*}$ Condition + Error(1/Neuron); $\mathrm{DF}=1,4790$.

tions seem to be stronger early in the interval, suggesting that the DMS may not be continuously integrating MFC input throughout the interval as DDMs might predict. Optogenetic studies that inhibit MFC input for specific epochs in the delay will be able to further test these possibilities. It is also unclear whether striatal ramping is necessary for cortical ramping given the anatomy of corticostriatal-thalamiccortical loops (Alexander et al., 1986; Roseberry et al., 2016).

Ramping activity can represent the accumulation of temporal evidence posited in DDMs and can readily emerge from recurrent network activity in cortical circuits (Durstewitz, 2003; Simen et al., 2011; Merchant and Averbeck, 2017). However, striatal circuits are organized quite differently from cortical circuits, receiving a minority of input from the MFC compared with other inputs (McFarland and Haber, 2000; Wall et al., 2013). The massive convergence of inputs onto striatal MSNs makes them ideally suited to filter ongoing MFC activity (McGeorge and Faull, 1989). We did not directly measure this convergence in our study by recording from synaptically-connected ramping neurons as this would require identifying layer V MFC neurons that contribute synaptic input to MSNs.

\section{Ramping and motor-related activity}

One key concern during fixed-interval timing tasks is that ramping activity is confounded with motor activity (Namboodiri and Hussain Shuler, 2014). We chose to use the previously described 
version of the interval-timing task because of its rich psychological history and clinical translatability (Malapani and Rakitin, 2003; Merchant et al., 2008, 2013; Ward et al., 2012; Parker et al., 2013b; Merchant and de Lafuente, 2014). Importantly, the ramping activity we report here cannot exclusively be explained by lever pressing alone for the following reasons: (1) most ramping neurons did not have significant lever-press modulation, (2) some frontostriatal neurons ramped over several seconds before the first lever press, (3) accurate NBC decoding was found in the first 4 s of FI12 trials when no lever presses occurred, (4) MFC-DMS interactions were strongest early in the interval and were not significant late in the interval when lever pressing was most prominent, and (5) MFC inactivation attenuated MSN ramping and MSN press-related activity as a function of inactivation and time without changing MSN press-related activity, including epochs when behavior was matched and epochs when there were no presses. We also could not detect any gross behavioral changes over the interval other than lever pressing, and our past work has repeatedly demonstrated that MFC inactivation does not affect lever pressing, per se (Narayanan and Laubach, 2006; Narayanan et al., 2012; Parker et al., 2014b, 2017).

We cannot rule out a role for ramping activity in motor preparation in this work or our past work involving fixed-hold periods (Narayanan and Laubach, 2006, 2009a). Indeed, rodents can use "embodied" strategies to solve behavioral problems (Cowen and McNaughton, 2007), as can humans (e.g., subvocal rehearsal; Baddeley, 1998), and there may be subtle preparatory movements that relate to ramping activity that we cannot measure. Indeed, even if ramping was related to such movements, our data clearly indicate that this signal is related to rodents' behavioral solutions to this instantiation of fixed-interval timing. Furthermore, the dependence of DMS ramping on the MFC indicates that DMS ramping is a key part of this signal. These data could be instructive in elucidating strategies to compensate for MFC dysfunction in this task (Kim et al., 2017; Parker et al., 2017).

\section{Frontostriatal activity and the starting gun during interval timing}

Our data provide new evidence regarding the proposed starting gun at trial onset that provides a "phase reset" and synchronizes frontostriatal ensembles at the beginning of timing tasks (Matell and Meck, 2004). We have previously found bursts of cuetriggered $\sim 4-\mathrm{Hz}$ MFC activity that are attenuated in Parkinson's patients and modulated by D1-dopamine receptors (Parker et al., 2014b, 2015a, 2015b; Chen et al., 2016). Dopamine neurons fire to reward-predictive stimuli across temporal delays and could encode this starting signal during interval timing (Schultz, 2001). Power of $\sim 4 \mathrm{~Hz}$ can also synchronize MFC ramping neurons (Parker et al., 2014b). Here, we provide evidence that DMS ramping neurons synchronize with $\mathrm{MFC} \sim 4-\mathrm{Hz}$ activity. We have previously found similar cross-area corticocortical spikefield coupling at $\sim 4 \mathrm{~Hz}$ between the motor cortex and the MFC after errors (Narayanan et al., 2013). These data suggest that cuetriggered low-frequency MFC activity - which has been associated with salience, conflict, and cognitive control—synchronizes neurons involved in temporal processing across frontostriatal networks.

Our study is limited in that we did not investigate detailed circuit anatomy in either the MFC or DMS. Indeed, layer V MFC neurons robustly project to both DMS MSNs and fast-spiking interneurons (FSIs; Shepherd, 2013). We did not sample enough FSIs to reliably study them in isolation. There are D1 and D2 MSNs in the direct and indirect pathway, respectively (Alexander and Crutcher, 1990; Calabresi et al., 2014), and we did not isolate these populations and thus cannot conclude if D1 or D2 MSNs preferentially ramp. Future studies with optogenetic "tagging" might be able to resolve this question with definitive cell-type specificity in transgenic D1/D2-Cre mice (Parker et al., 2016). In addition, our data posit strong functional MFC-DMS convergence, but we have no synaptic evidence to support this idea. We also did not specifically inactivate MFC projections to the DMS. Thus, our inactivation results might be an indirect effect. Combining retrograde virus and optogenetic techniques has the potential to directly test this idea (Yizhar et al., 2011). We did not find any behavioral changes during the interval that could explain ramping-related activity. However, there may be other techniques that capture other, more subtle movements that contribute to the temporal control of action and could explain the ramping activity we observed (Cowen and McNaughton, 2007). Despite these caveats, these data provide insight into fundamental information processing in frontostriatal circuits that could have relevance for understanding how these circuits might malfunction in human disease.

\section{References}

Aertsen AM, Gerstein GL (1985) Evaluation of neuronal connectivity: sensitivity of cross-correlation. Brain Res 340:341-354. CrossRef Medline

Alexander GE, Crutcher MD (1990) Functional architecture of basal ganglia circuits: neural substrates of parallel processing. Trends Neurosci 13:266271. CrossRef Medline

Alexander GE, DeLong MR, Strick PL (1986) Parallel organization of functionally segregated circuits linking basal ganglia and cortex. Annu Rev Neurosci 9:357-381. CrossRef Medline

Allen TA, Narayanan NS, Kholodar-Smith DB, Zhao Y, Laubach M, Brown TH (2008) Imaging the spread of reversible brain inactivations using fluorescent muscimol. J Neurosci Methods 171:30-38. CrossRef Medline

Baddeley A (1998) The central executive: a concept and some misconceptions. J Int Neuropsychol Soc JINS 4:523-526. CrossRef Medline

Bakhurin KI, Goudar V, Shobe JL, Claar LD, Buonomano DV, Masmanidis SC (2017) Differential encoding of time by prefrontal and striatal network dynamics. J Neurosci 37:854-870. CrossRef Medline

Bekolay T, Laubach M, Eliasmith C (2014) A spiking neural integrator model of the adaptive control of action by the medial prefrontal cortex. J Neurosci 34:1892-1902. CrossRef Medline

Berke JD, Okatan M, Skurski J, Eichenbaum HB (2004) Oscillatory entrainment of striatal neurons in freely moving rats. Neuron 43:883-896. CrossRef Medline

Buhusi CV, Meck WH (2005) What makes us tick? Functional and neural mechanisms of interval timing. Nat Rev Neurosci 6:755-765. CrossRef Medline

Calabresi P, Picconi B, Tozzi A, Ghiglieri V, Di Filippo M (2014) Direct and indirect pathways of basal ganglia: a critical reappraisal. Nat Neurosci 17:1022-1030. CrossRef Medline

Cavanagh JF, Frank MJ (2014) Frontal theta as a mechanism for cognitive control. Trends Cogn Sci 18:414-421. CrossRef Medline

Cavanagh JF, Cohen MX, Allen JJ (2009) Prelude to and resolution of an error: EEG phase synchrony reveals cognitive control dynamics during action monitoring. J Neurosci 29:98-105. CrossRef Medline

Chapin JK, Nicolelis MA (1999) Principal component analysis of neuronal ensemble activity reveals multidimensional somatosensory representations. J Neurosci Methods 94:121-140. CrossRef Medline

Chen KH, Okerstrom KL, Kingyon JR, Anderson SW, Cavanagh JF, Narayanan NS (2016) Startle habituation and midfrontal theta activity in Parkinson's disease. J Cogn Neurosci 28:1923-1932. CrossRef Medline

Chuhma N, Tanaka KF, Hen R, Rayport S (2011) Functional connectome of the striatal medium spiny neuron. J Neurosci 31:1183-1192. CrossRef Medline

Coull JT, Cheng RK, Meck WH (2011) Neuroanatomical and neurochemical substrates of timing. Neuropsychopharmacology 36:3-25. CrossRef Medline

Cowen SL, McNaughton BL (2007) Selective delay activity in the medial prefrontal cortex of the rat: contribution of sensorimotor information and contingency. J Neurophysiol 98:303-316. CrossRef Medline 
Dejean C, Courtin J, Karalis N, Chaudun F, Wurtz H, Bienvenu TC, Herry C (2016) Prefrontal neuronal assemblies temporally control fear behaviour. Nature 535:420-424. CrossRef Medline

Donnelly NA, Paulsen O, Robbins TW, Dalley JW (2015) Ramping single unit activity in the medial prefrontal cortex and ventral striatum reflects the onset of waiting but not imminent impulsive actions. Eur J Neurosci 41:1524-1537. CrossRef Medline

Durstewitz D (2003) Self-organizing neural integrator predicts interval times through climbing activity. J Neurosci 23:5342-5353. Medline

Emmons EB, Ruggiero RN, Kelley RM, Parker KL, Narayanan NS (2016) Corticostriatal field potentials are modulated at delta and theta frequencies during interval-timing task in rodents. Front Psychol 7:459. CrossRef Medline

Gabbott PL, Warner TA, Jays PR, Salway P, Busby SJ (2005) Prefrontal cortex in the rat: projections to subcortical autonomic, motor, and limbic centers. J Comp Neurol 492:145-177. CrossRef Medline

Gold JI, Shadlen MN (2007) The neural basis of decision making. Annu Rev Neurosci 30:535-574. CrossRef Medline

Gouvea TS, Monteiro T, Motiwala A, Soares S, Machens C, Paton JJ (2015) Striatal dynamics explain duration judgments. eLife 4.pii:e11386. CrossRef Medline

Halliday DM, Rosenberg JR, Amjad AM, Breeze P, Conway BA, Farmer SF (1995) A framework for the analysis of mixed time series/point process data - theory and application to the study of physiological tremor, single motor unit discharges and electromyograms. Prog Biophys Mol Biol 64: 237-278. CrossRef Medline

Histed MH, Pasupathy A, Miller EK (2009) Learning substrates in the primate prefrontal cortex and striatum: sustained activity related to successful actions. Neuron 63:244-253. CrossRef Medline

Jin X, Tecuapetla F, Costa RM (2014) Basal ganglia subcircuits distinctively encode the parsing and concatenation of action sequences. Nat Neurosci 17:423-430. CrossRef Medline

Joliffe I (2002) Principal component analysis, 1st ed. New York: Springer.

Kim J, Jung AH, Byun J, Jo S, Jung MW (2009) Inactivation of medial prefrontal cortex impairs time interval discrimination in rats. Front Behav Neurosci 3:38. CrossRef Medline

Kim J, Ghim JW, Lee JH, Jung MW (2013) Neural correlates of interval timing in rodent prefrontal cortex. J Neurosci 33:13834-13847. CrossRef

Kim YC, Han SW, Alberico SL, Ruggiero RN, De Corte B, Chen KH, Narayanan NS (2017) Optogenetic stimulation of frontal D1 neurons compensates for impaired temporal control of action in dopamine-depleted mice. Curr Biol 27:39-47. CrossRef Medline

Kimchi EY, Laubach M (2009) Dynamic encoding of action selection by the medial striatum. J Neurosci 29:3148-3159. CrossRef Medline

Laubach M, Caetano MS, Narayanan NS (2015) Mistakes were made: neural mechanisms for the adaptive control of action initiation by the medial prefrontal cortex. J Physiol Paris 109:104-117. CrossRef Medline

Ma L, Hyman JM, Phillips AG, Seamans JK (2014a) Tracking progress toward a goal in corticostriatal ensembles. J Neurosci 34:2244-2253. CrossRef Medline

Ma L, Hyman JM, Lindsay AJ, Phillips AG, Seamans JK (2014b) Differences in the emergent coding properties of cortical and striatal ensembles. Nat Neurosci 17:1100-1106. CrossRef Medline

Malapani C, Rakitin BC (2003) Interval timing in the dopamine-depleted basal ganglia: from empirical data to timing theory. In: Functional and neural mechanisms of interval timing, pp 485-514. Boca Raton, FL: CRC.

Malapani C, Rakitin B, Levy R, Meck WH, Deweer B, Dubois B, Gibbon J (1998) Coupled temporal memories in Parkinson's disease: a dopaminerelated dysfunction. J Cogn Neurosci 10:316-331. CrossRef Medline

Matell MS, Meck WH (2004) Cortico-striatal circuits and interval timing: coincidence detection of oscillatory processes. Brain Res Cogn Brain Res 21:139-170. CrossRef Medline

Matell MS, Meck WH, Nicolelis MA (2003) Interval timing and the encoding of signal duration by ensembles of cortical and striatal neurons. Behav Neurosci 117:760-773. CrossRef Medline

McFarland NR, Haber SN (2000) Convergent inputs from thalamic motor nuclei and frontal cortical areas to the dorsal striatum in the primate. J Neurosci 20:3798-3813. Medline

McGeorge AJ, Faull RL (1989) The organization of the projection from the cerebral cortex to the striatum in the rat. Neuroscience 29:503-537. CrossRef Medline

Meck WH (2006) Neuroanatomical localization of an internal clock: a func- tional link between mesolimbic, nigrostriatal, and mesocortical dopaminergic systems. Brain Res 1109:93-107. CrossRef Medline

Mello GB, Soares S, Paton JJ (2015) A scalable population code for time in the striatum. Curr Biol 25:1113-1122. CrossRef Medline

Merchant H, Averbeck BB (2017) The computational and neural basis of rhythmic timing in medial premotor cortex. J Neurosci 37:4552-4564. CrossRef Medline

Merchant H, de Lafuente V (2014) Introduction to the neurobiology of interval timing. Adv Exp Med Biol 829:1-13. CrossRef Medline

Merchant H, Luciana M, Hooper C, Majestic S, Tuite P (2008) Interval timing and Parkinson's disease: heterogeneity in temporal performance. Exp Brain Res 184:233-248. CrossRef Medline

Merchant H, Harrington DL, Meck WH (2013) Neural basis of the perception and estimation of time. Annu Rev Neurosci 36:313-336. CrossRef Medline

Namboodiri VM, Hussain Shuler MG (2014) Report of interval timing or action? Proc Natl Acad Sci U S A 111:E2239. CrossRef Medline

Narayanan NS (2016) Ramping activity is a cortical mechanism of temporal control of action. Curr Opin Behav Sci 8:226-230. CrossRef Medline

Narayanan NS, Laubach M (2006) Top-down control of motor cortex ensembles by dorsomedial prefrontal cortex. Neuron 52:921-931. CrossRef Medline

Narayanan NS, Laubach M (2008) Neuronal correlates of post-error slowing in the rat dorsomedial prefrontal cortex. J Neurophysiol 100:520-525. CrossRef Medline

Narayanan NS, Laubach M (2009a) Delay activity in rodent frontal cortex during a simple reaction time task. J Neurophysiol 101:2859-2871. CrossRef Medline

Narayanan NS, Laubach M (2009b) Methods for studying functional interactions among neuronal populations. In: Dynamic brain imaging (Hayder, F, ed.), pp 135-165. Cham, Switzerland: Springer.

Narayanan NS, Laubach M (2017) Inhibitory control: mapping medial frontal cortex. Curr Biol CB 27:R148-R150. CrossRef Medline

Narayanan NS, Horst NK, Laubach M (2006) Reversible inactivations of rat medial prefrontal cortex impair the ability to wait for a stimulus. Neuroscience 139:865-876. CrossRef Medline

Narayanan NS, Land BB, Solder JE, Deisseroth K, DiLeone RJ (2012) Prefrontal D1 dopamine signaling is required for temporal control. Proc Natl Acad Sci U S A 109:20726-20731. CrossRef Medline

Narayanan NS, Cavanagh JF, Frank MJ, Laubach M (2013) Common medial frontal mechanisms of adaptive control in humans and rodents. Nat Neurosci 16:1888-1895. CrossRef Medline

Parker KL, Kim YC, Kelley RM, Nessler AJ, Chen KH, Muller-Ewald VA, Andreasen NC, Narayanan NS (2017) Delta-frequency stimulation of cerebellar projections can compensate for schizophrenia-related medial frontal dysfunction. Mol Psychiatry 22:647-655. CrossRef Medline

Parker KL, Alberico SL, Miller AD, Narayanan NS (2013a) Prefrontal D1 dopamine signaling is necessary for temporal expectation during reaction time performance. Neuroscience 255:246-254. CrossRef Medline

Parker KL, Lamichhane D, Caetano MS, Narayanan NS (2013b) Executive dysfunction in Parkinson's disease and timing deficits. Front Integr Neurosci 7:75. CrossRef Medline

Parker KL, Narayanan NS, Andreasen NC (2014a) The therapeutic potential of the cerebellum in schizophrenia. Front Syst Neurosci 8:163. CrossRef Medline

Parker KL, Chen KH, Kingyon JR, Cavanagh JF, Narayanan NS (2014b) D1-dependent $4 \mathrm{~Hz}$ oscillations and ramping activity in rodent medial frontal cortex during interval timing. J Neurosci 34:16774-16783. CrossRef Medline

Parker KL, Chen KH, Kingyon JR, Cavanagh JF, Narayanan NS (2015a) Medial frontal $\sim 4 \mathrm{~Hz}$ activity in humans and rodents is attenuated in PD patients and in rodents with cortical dopamine depletion. J Neurophysiol 114:1310-1320. CrossRef Medline

Parker KL, Ruggiero RN, Narayanan NS (2015b) Infusion of D1 dopamine receptor agonist into medial frontal cortex disrupts neural correlates of interval timing. Front Behav Neurosci 9:294. CrossRef Medline

Parker KL, Kim Y, Alberico SL, Emmons EB, Narayanan NS (2016) Optogenetic approaches to evaluate striatal function in animal models of Parkinson disease. Dialogues Clin Neurosci 18:99-107. Medline

Pasupathy A, Miller EK (2005) Different time courses of learning-related activity in the prefrontal cortex and striatum. Nature 433:873-876. CrossRef Medline 
Philiastides MG, Auksztulewicz R, Heekeren HR, Blankenburg F (2011) Causal role of dorsolateral prefrontal cortex in human perceptual decision making. Curr Biol 21:980-983. CrossRef Medline

Risterucci C, Terramorsi D, Nieoullon A, Amalric M (2003) Excitotoxic lesions of the prelimbic-infralimbic areas of the rodent prefrontal cortex disrupt motor preparatory processes. Eur J Neurosci 17:1498-1508. Medline

Roseberry TK, Lee AM, Lalive AL, Wilbrecht L, Bonci A, Kreitzer AC (2016) Cell-type-specific control of brainstem locomotor circuits by basal ganglia. Cell 164:526-537. CrossRef Medline

Rosenberg JR, Amjad AM, Breeze P, Brillinger DR, Halliday DM (1989) The Fourier approach to the identification of functional coupling between neuronal spike trains. Prog Biophys Mol Biol 53:1-31. Medline

Schultz W (2001) Reward signaling by dopamine neurons. Neuroscientist 7:293-302. CrossRef Medline

Shepherd GM (2013) Corticostriatal connectivity and its role in disease. Nat Rev Neurosci 14:278-291. CrossRef Medline

Simen P, Balci F, de Souza L, Cohen JD, Holmes P (2011) A model of interval timing by neural integration. J Neurosci 31:9238-9253. CrossRef Medline
Stokes MG, Kusunoki M, Sigala N, Nili H, Gaffan D, Duncan J (2013) Dynamic coding for cognitive control in prefrontal cortex. Neuron 78:364375. CrossRef Medline

Wall NR, De La Parra M, Callaway EM, Kreitzer AC (2013) Differential innervation of direct- and indirect-pathway striatal projection neurons. Neuron 79:347-360. CrossRef Medline

Ward RD, Kellendonk C, Kandel ER, Balsam PD (2012) Timing as a window on cognition in schizophrenia. Neuropharmacology 62:1175-1181. CrossRef Medline

Witten I, Frank E (2000) Data mining. San Diego: Academic.

Xu LQ, Li Y (2003) Video classification using spatial-temporal features and PCA. In: Proceedings of the International Conference on Multimedia and Expo (ICME '03), vol. 3, pp 485-488, Baltimore, MD, July.

Xu M, Zhang SY, Dan Y, Poo MM (2014) Representation of interval timing by temporally scalable firing patterns in rat prefrontal cortex. Proc Natl Acad Sci U S A 111:480-485. CrossRef Medline

Yizhar O, Fenno LE, Davidson TJ, Mogri M, Deisseroth K (2011) Optogenetics in neural systems. Neuron 71:9-34. CrossRef Medline 